CDD: 149.9

\title{
CRÍTICA AL PSICOLOGISMO Y CONCEPCIÓN DE SUBJETIVIDAD EN FREGE
}

\author{
MARIO ARIEL GONZÁLEZ PORTA \\ Pontificia Universidade Católica - São Paulo \\ mariopor@pucsp.br
}

Received:15.10.2013; Revised:04.05.20 I4; Accepted:1 7.06.2014

Resumen: La remisión del problema relativo al como de la captación de pensamientos a la psicología por parte de Frege ha llevado a que se imponga entre los críticos la idea de que toda consideración subjetiva está ausente en este autor. La crítica fregueana al psicologismo, sin embargo, se concentra en una crítica a la concepción psicologista de subjetividad y, correlativamente, implica una concepción de subjetividad novedosa en el contexto de la filosofía alemana de la segunda mitad del s. XIX que, como la husserliana, es no-naturalística e intencional.

\begin{abstract}
Frege regards the problem of how a thought is grasped as belonging to psychology, and this has made the idea that all subjective considerations are absent from his work a dominant trend amongst the critics. The fregean criticism of psychologism, however, focusses on a criticism of the psychologistic conception of subjectivity and, accordingly, implies a conception of subjectivity that is new in the context of the German philosophy of the second half of the $19^{\text {th }}$ century and that is, like Husserl's, non-naturalistic and intentional.
\end{abstract}

Palabras clave: Frege, psychologism, subjectivity

Keywords: Frege, psychologism, subjectivity

Manuscrito - Rev. Int. Fil., Campinas, v. 37, n.2, pp. 357-413, jul.-dez. 2014. 


\section{Introducción ${ }^{1}$}

1. El objetivo de la siguiente contribución es corregir una visión errada de Frege con respecto al nexo que existe entre su crítica al psicologismo y el tema de la subjetividad. Para ello es imprescindible, sin embargo, reconstruir en trazos generales un contexto mucho más amplio, únicamente en el marco del cual el análisis que habremos de efectuar adquiere su verdadero sentido.

\section{La lucha antipsicologista en el contexto de la filosofía alemana pos-Hegel}

1. Es necesario escribir una historia de la polémica antipsicologista, pues hasta ahora no existe ninguna ${ }^{2}$. Una de las mayores dificultades de este "libro futuro"3 sería, sin duda, encontrar un hilo conductor suficientemente abarcador o adecuadamente amplio, para exponer un proceso que, por un lado, recorre varias etapas, por otro, posee diversas vertientes.

2. De todas formas, de lo que no cabe duda es de que el referido "libro futuro" debería comenzar con la frase: "En el comienzo fue Hegel". En efecto: los orígenes del psicologismo hunden sus raíces en la situación de la filosofía alemana pos-Hegel, más concretamente, en la masiva reacción a toda metafísica y filosofía especulativa que condujo a una reorientación del pensar a lo "dado" (Gegebenheit). Esta reorientación habrá de adquirir dos formas radicalmente diversas. Por un lado,

\footnotetext{
${ }^{1}$ Cito textos de los autores estudiados por abreviaciones y de comentadores por año.

${ }^{2}$ Los trabajos más completos y, no obstante, aún parciales, son los de Kusch (1993) y Rath (1994).

3 Tomo prestada una expresión usada en otro contexto por el filósofo uruguayo Carlos Alberto Vaz Ferreira en su obra "Fermentario".
}

Manuscrito - Rev. Int. Fil., Campinas, v. 37, n.2, pp. 357-413, jul.-dez. 2014. 
restablecer la relación de la filosofía con la ciencia, transformando la primera en una reflexión sobre la segunda, y, por otro, identificar la filosofía con una ciencia específica y de particular pujanza en la época, la psicología. Dicho de otra forma, el psicologismo es la consecuencia del virulento inmanentismo surgido como reacción al idealismo poskantiano.

3. El "principio de inmanencia" (PI) es la fuente del psicologismo imperante en la filosofía alemana del siglo XIX. Como me he de referir a dicho principio de forma repetida, importa que lo defina en un inicio. Por tal entenderé la fundamental convicción cartesiana ${ }^{4}$, explicitada en forma clásica por Locke ${ }^{5}$, de que los únicos objetos inmediatos de mi conciencia son sus propios contenidos reales (Bewusstseinsinhalte), o sea, sus ideas (ideas) o representaciones (Vorstellungen). Ya de la propia definición aportada surge con claridad, que el PI no es una peculiaridad de la filosofía alemana pos-Hegel, sino que sus orígenes se identifican con los de la propia filosofía moderna. No obstante, es importante observar que, en el contexto de la filosofía alemana pos-Hegel, este principio adquiere un lugar central, convirtiéndose en uno de los verdaderos axiomas indiscutidos de la época. Lo anterior significa, por un lado, que el PI está en la base del psicologismo y lo motiva ${ }^{6}$, por

\footnotetext{
${ }^{4}$ Compárese Blumenberg (1959, p. 993).

${ }^{5}$ Locke: Essay, Book II, Ch. I, p. 1 y Book IV, I, p. 1.

${ }^{6}$ Un papel decisivo para la vigencia del PI en el s. XIX alemán lo juega sin duda Schopenhauer (WWV, I, $\$ 1$, p. 3s.) y, en última instancia, Reinhold (VNTMV). Con respecto a la presencia del PI en los lógicos psicologistas más influyentes, recordemos Sigwart (L, $₫ 1,6$, p. 6-7), Wundt (L, I, p. 12), Lipps (GL, $\$ 3$, p. $1-2, \S 5$, p. $2-3$ y $\$ 7$, p. 8 ), Schuppe (GEL, $\$ 25$, p. 18 y $\$ 43$, p. 35$)$ y Erdmann (LE, \$8, p. 35 y \$35, p. 187).
}

Manuscrito - Rev. Int. Fil., Campinas, v. 37, n.2, pp. 357-413, jul.-dez. 2014. 
otro, sin embargo, que él domina también las filas de los antipsicologistas 7 .

4. Decíamos que el surgimiento del psicologismo es simultáneo al surgimiento de la concepción de la filosofía como reflexión sobre la ciencia. De tal concepción se nutrirá la reacción antipsicologista. Ahora bien, existen dos vertientes diferenciables del antipsicologismo, la una, de cuño platónico; la otra, lógico-transcendental. Pese todas las diferencias entre ambas, hay algunos importantes rasgos comunes que motivan una similar (aun cuando no absolutamente idéntica) objeción de parte de los psicologistas y que se deja resumir con el título de "objetivismo", con el cual se apunta a subrayar de una forma u otra la desconsideración del carácter en última instancia subjetivo del conocimiento. La línea de confrontación entre psicologistas y antipsicologistas gira en torno a la oposición "objetivismo"-relativismo.

5. Si comenzamos con el antipsicologismo de cuño platónico, digamos que ya Exner objetaba a Bolzano, que la admisión de "representaciones en sí", objetivas e irreales, nos enfrenta al problema irresoluble de cómo un sujeto real, como en última instancia lo es el sujeto del conocimiento, puede acceder a algo que, de principio, no es real, una objeción que, obviamente, tiene su raíz última en la presuposición incondicional del PI, o sea, en este caso, en que solo puedo captar lo que de algún modo es real "en mí"8. Bolzano intenta varias respuestas a esta objeción, pero ninguna es convincente, en última instancia, porque

\footnotetext{
${ }^{7}$ Véase las notas al pie de página 14, 27, 29. La presencia del PI en la filosofía alemana del siglo XIX es tan masiva que incluso un neohegeliano como Kuno Fischer lo suscribe (SLM, p. 477). Frege cita otra obra de Fischer en GA, p. III-IV (5).

${ }^{8}$ Exner a Bolzano 10/12/1834, p. $74-75$ y 78 .
}

Manuscrito - Rev. Int. Fil., Campinas, v. 37, n.2, pp. 357-413, jul.-dez. 2014. 
en todas ellas no consigue evidenciar el supuesto de Exner, concediendo a este sin más los derechos de una psicología naturalista9 ${ }^{9}$.

6. La tendencia objetivista de los antipsicologistas se mantiene, aun cuando en otra variante, en la vertiente lógico-transcendental, impulsada por el neokantianismo, siendo decisiva tanto en Cohen cuanto en Windelband ${ }^{10}$. Como consecuencia de su tajante distinción de todo lo psicológico, la así llamada "conciencia transcendental" deviene en realidad una mera façon de parler, que no expresa otra cosa que el conjunto sistemático de principios de validez. No obstante, surgirá de las propias filas neokantianas, y por un proceso inmanente, el intento de superación de esta tendencia. Natorp es el primero en comprender que, al final de cuentas, una filosofía transcendental sin sujeto es un sin-sentido y que toda crítica al psicologismo que no dé cuenta de su justa exigencia subjetiva, estará condenada al fracaso. De este modo, y por primera vez en la historia de la polémica, Natorp concentra su crítica al psicologismo en una crítica del concepto psicologista de subjetividad. Su tesis fundamental, que lo opondrá al psicologismo no menos que al "logicismo" radical de Cohen, reza: el psicologismo es la consecuencia de una falsa teoría de la subjetividad, propia del naturalismo (y, en última instancia del dualismo) y, por tanto, solo puede ser definitivamente superado si se supera esta. Sobre esta base, la salida que Natorp propone es disolver la rígida oposición sujeto-objeto, presupuesta en toda visión naturalista de la subjetividad, substituyéndola por una oposición relativa entre subjetivación y

9 Un estudio de la polémica ofrece González Porta, 2002 y 2003.

10 Brelage, 1965, p. 94-95. Compárese González Porta, 1989, p. 12-14 y 2011, p. 201 ss.

Manuscrito - Rev. Int. Fil., Campinas, v. 37, n.2, pp. 357-413, jul.-dez. 2014. 
objetivación como diferentes direcciones en que se puede considerar un único proceso fundamental ${ }^{11}$.

7. Si queremos entender el desenvolvimiento posterior que tomará la lucha antipsicologista y, en particular, el papel que Frege habrá de desempeñar en la misma, tenemos que observar que, junto con el mencionado cambio fundamental, existe en Natorp otro punto en el cual él conserva el status quo, a saber, en el mantenimiento del PI. En tal sentido, salvemos del olvido un hecho importante, a saber, que en 1894, cuando Twardowsky escribe su histórico texto "Sobre contenido y objeto de la representación", Natorp le dedica una reseña en donde del contexto surge que él considera que Twardowsky se encuentra en la dirección errada ${ }^{12}$, impresión que se reafirma si se atiende a la correspondencia con Husserl de esa época ${ }^{13}$ y se confirma definitivamente en textos posteriores ${ }^{14}$.

11 Dado el contexto de mi análisis, hago referencia en el presente trabajo únicamente a los primeros textos natorpianos vinculados a la crítica del psicologismo y propuesta de una nueva psicología que supere el concepto psicologista de sujeto (1887-1893). En textos posteriores pueden encontrarse con certeza formulaciones más incisivas en el sentido del análisis propuesto. A ellas ya me he referido por extenso en otros momentos (González Porta, 1989, p. 80ss. y 2011, p. 210ss.). Ahora bien, es difícil efectuar citas suficientemente inequívocas y adecuadamente cortas en base a los primeros textos. Por tal razón, remito al lector a los tres últimos parágrafos de la "Einleitung in die Psychologie nach kritischer Methode“ (\$13. Rekonstruktion der Subjektivität als eigentümliche Aufgabe der Psychologie, p. 88ss.; \$14. Objektive und subjektive Begründung der Erkenntnis. Wahrheit und Schein des Idealismus, p. 103ss. y \$15. Wechselbeziehung von Psychologie und Erkenntniskritik, p. 119ss.) así como ÜOSM, p. 285-286. Un texto que se aproxima a reunir de modo condensado los diferentes elementos de la posición natorpiana se encuentra en EPs, p. 119-120.

${ }^{12}$ Natorp, BDSE, II, p. 198-201.

13 Cartas de Husserl a Natorp del 16/1/97; Natorp a Husserl, 17/1/1897; Husserl a Natorp, 21/1/1897; Natorp a Husserl, 1/2/1897; Husserl a Natorp,

Manuscrito - Rev. Int. Fil., Campinas, v. 37, n.2, pp. 357-413, jul.-dez. 2014. 
8. Mas, al mencionar a Twardowsky he introducido un nuevo y decisivo protagonista de nuestra historia, sobre el cual conviene detenernos. Me refiero a Franz Brentano y a su escuela como un todo. En la medida en que el Neokantianismo termina imponiéndose en Alemania en torno a la década del 70 del siglo XIX, la polémica en torno al psicologismo pasa a concentrarse en una polémica entre el "método psicológico" y el "método transcendental"15. Ahora bien, debemos tener sumo cuidado al establecer la relación entre psicologismo y método psicológico. En el origen, tanto del psicologismo como del método psicológico se encuentran Fries y Benecke y, sin duda, todos los psicologistas propugnaban de un modo u otro, aun cuando con importantes diferencias, el método psicológico. No obstante lo anterior, sería un

3/2/1987 y Natorp a Husserl, 8/3/1897 (Hua, Briefwechsel. Band V, p. 39$58)$.

${ }^{14} \mathrm{AP}$, p. 153. Confiérase la extensa discusión del tema con Lipps, Brentano, Meinong y Husserl en AP, p. 270-290 en donde Natorp opone a toda distinción absoluta entre Inbalt y Gegenstand, la distinción puramente relativa y funcional de las direcciones de objetivación y subjetivación.

${ }^{15}$ Entiendo por "método psicológico" el tratamiento de problemas lógicos, epistemológicos y/o semánticos que se funda en la consideración de eventos psíquicos; por "método transcendental", el establecimiento lógico-reflexivo de las condiciones de posibilidad del conocimiento. La idea de un "método transcendental" se torna patrimonio común del neokantianismo con Hermann Cohen a partir de 1876 (KBE, V). Con ella se pretendía subrayar el carácter lógico-objetivo (o sea, no psicológico), de la empresa "crítica" kantiana. La oposición de las expresiones "método psicológico"-"método transcendental" deviene canónica por lo menos a partir Max Scheler (TPsM). En el contexto de la discusión neo-kantiana de la segunda mitad del siglo XIX eran usuales otras contraposiciones como, por ejemplo (y principalmente) entre "kritische" y "genetische Methode" (Windelband: P, p. 318ss.). Si, no obstante lo anterior, opto por usar la oposición entre "método psicológico" y "método transcendental", es porque en el caso de Brentano explícitamente se distingue entre psicología genética y descriptiva (DP, p. 1-5), o sea que, en este autor, el "método psicológico" no coincide, como en muchos otros autores de la época, con el "método genético".

Manuscrito - Rev. Int. Fil., Campinas, v. 37, n.2, pp. 357-413, jul.-dez. 2014. 
gran error pasar por alto que, si bien Brentano es más un defensor del método psicológico, sin embargo se opuso desde siempre a todo relativismo y, dado su intransigente realismo de cuño aristotélico, no sin razón, resistió con vehemencia todo intento de sospechar en él un psicologismo $^{16}$.

9. Ciertamente debemos tomar en serio los descargos de Brentano. Mas para que la necesidad de los mismos sea comprensible, tiene que darse la importancia que merece a la misma posibilidad de tales acusaciones. Quizás sin querer, quizás de un modo injusto, quizás por mera ironía del destino, el hecho histórico innegable es que Brentano otorga un nuevo impulso al inmanentismo con su redescubrimiento del concepto de intencionalidad. El texto de Twardowsky que da inicio a la discusión sobre las relaciones entre contenido y objeto y que, como vimos, habrá de concentrar el foco de la discusión mucho más allá de los límites de la escuela de Brentano, surge justamente en ella y como crítica al maestro.

\section{El lugar singular de Frege en la historia de la lucha antipsicologista}

1. Esta larga introducción fue absolutamente necesaria, pues en ella hemos establecido los dados fundamentales, por regla general o desconocidos o ignorados, solo a partir de las cuales es posible fijar correctamente cuál es el lugar singular que Frege ocupa en la historia de la polémica en torno al psicologismo.

2. Podemos (y debemos) considerar la crítica fregueana al psicologismo en tres perspectivas que, aun cuando radicalmente diferentes, en última instancia se complementan, dado que los resultados de la una potencializan la significación de los resultados de las otras. Podemos

16 PES, II, p. 179 ss.

Manuscrito - Rev. Int. Fil., Campinas, v. 37, n.2, pp. 357-413, jul.-dez. 2014. 
ver la crítica fregueana al psicologismo de un modo puramente sistemático, de uno genético-evolutivo o, finalmente, contextualizar la misma situándola en relación con sus contemporáneos.

3. Si consideramos la crítica fregueana al psicologismo de un modo puramente sistemático, entonces tenemos que constatar que la misma no es una unidad lógicamente articulada, sino que se compone de diferentes momentos que poseen un relativo grado de autonomía entre sí. Podemos ordenar los argumentos fregueanos en dos tipos, aquellos que apuntan a denunciar una confusión y aquellos que apuntan a denunciar una tesis falsa ${ }^{17}$.

a. Entre los argumentos por confusión están aquellos que exigen una diferenciación correlativa como, por ejemplo, entre questio facti y questio iuris ${ }^{18}$, o entre dos sentidos de representación (Vorstellung), subjetivo y objetivo ${ }^{19}$, o entre ser verdadero y tener por verdadero (Wabrsein-Fürwabrhalten $)^{20}$, o entre pensar y pensamiento (denken y Gedanke) ${ }^{21}$, o entre dos sentidos del concepto de ley, normativo y descriptivo ${ }^{22}$, o entre objetivo y real (Objektivität—Wirklichkeit) ${ }^{23}$, etc.

b. Los argumentos por falsedad son básicamente de dos tipos, a saber, los que refutan el psicologismo por sus consecuencias y los que lo hacen por sus presupuestos. Argumentos del primer

17 Ciertamente puede intentarse sistematizar todos los argumentos usados contra el psicologismo por sus detractores. En tal caso sería necesario completar la lista ofrecida en los dos ítems diferenciados, además de introducir otros, principalmente, la acusación de circularidad.

18 Beg, p. IX; GA, p. 7; L (1897), p. 67; L (1879-1891), p. 2.

${ }^{19} \mathrm{GA}, \$ 27 \mathrm{n} ; \mathrm{RH}$, p. 328; GGA, p. XVIII.

${ }^{20}$ GGA, p. XV-XVI.

${ }^{21}$ L (1897), pp. 34, 37 y 42; G, pp. 35 (62) y 50 (75); SB, p. 46; LM, p. 18.

22 GGA, p. XV.

$23 \mathrm{GA}, \S 27$.

Manuscrito - Rev. Int. Fil., Campinas, v. 37, n.2, pp. 357-413, jul.-dez. 2014. 
tipo son aquellos que apuntan a mostrar que el psicologismo necesariamente conduce al relativismo y que este termina negando la condición de inteligibilidad de su propia afirmación ${ }^{24}$. Argumentos del segundo tipo son aquellos que apuntan a mostrar que el psicologismo deriva de una concepción falsa de subjetividad.

4. Si ahora vinculamos estos resultados al punto de vista de la relación entre Frege y sus contemporáneos, tenemos:

a. que todos los argumentos del primer tipo y la casi totalidad de los del segundo, pueden ser encontrados en diferentes variantes en otros antipsicologistas. No con el objeto de prueba, sino meramente de ejemplificación, recordemos que la distinción quid iuris - quid facti arranca de Kant y recorre el siglo XIX, sobre todo a través de aquellos filósofos que, de un modo u otro, "retornan" a él. Otras distinciones como, por ejemplo, entre pensar y pensamiento (denken y Gedanke) aparecen en modos similares en otros autores, como, por ejemplo, entre conocer y conocimiento (erkennen und Erkenntnis) en Cohen ${ }^{25}$, o de un modo más genérico entre acto y contenido ( $A k t$ und Inhalt) ${ }^{26}$. La distinción entre objetivo y real, por otra parte, tiene su origen en la reformulación de la teoría de las ideas platónicas por Lotze ${ }^{27}$.

${ }^{24}$ L (1897), p. 45-46. Compárese González Porta, 2009.

25 PI, \4-13, pp. 44-53; LRE, p. 3ss.

${ }^{26}$ La distinción entre acto y contenido era común entre los psicologistas y no garantiza por sí una superación del psicologismo. Algunos críticos, como Kutschera (1989, p. 162ss.), parecen desconocer este hecho, atribuyendo a tal distinción un papel central en la superación fregueana del psicologismo.

${ }^{27}$ Lotze: L, Drittes Buch, \297ss, p. 477ss. 
b. Existe en el segundo tipo de argumentos, no obstante, uno que solo encontramos en Frege y que consiste en la crítica de la concepción psicologista de subjetividad basada en la negación del PI. Aquí hay dos puntos a ser subrayados.

c. Ya en varias oportunidades hemos usado la expresión "polémica" en torno al psicologismo y lo hemos hecho de un modo consciente, para eliminar la falsa idea de que solo hubo una crítica al psicologismo. En efecto, el psicologismo no recibió pasivamente los ataques de sus detractores, sino que trabó una lucha con estos, una lucha en la cual, como sugerimos, argumentos y contrargumentos fueron opuestos unos a otros. Ahora bien, entender el carácter de polémica de la cuestión psicologista es importante para percibir un rasgo esencial de la misma que tiende a pasar desapercibido y que produce no pocas confusiones, a saber, que esta polémica, a diferencia de otras, no tuvo lugar entre dos partidos previamente definidos, sino que consistió en buena medida en una permanente redefinición de los mismos. Al definir el psicologismo por el PI, Frege está re-trazando la línea demarcatoria entre los oponentes, de forma tal que, según el criterio fregueano, pasan a ser psicologistas (o, al menos, no han superado plenamente el psicologismo) muchos autores que, desde otro punto de vista, pueden ser considerados como antipsicologistas (por ejemplo, Lotze ${ }^{28}$, Natorp ${ }^{29}$ y Rickert $^{30}$, entre muchos otros).

d. Obsérvese, que recién ahora deviene comprensible porque era tan importante establecer un contexto de discusión en el cual el papel de Natorp fuera resaltado. Frege no es el primero en

${ }^{28}$ Lotze: L, §306, p. 493. Compárese Lotze: „Die Philosophie in den letzten 40 Jahren“ (L, p. CVIII-CIX.))

${ }^{29}$ Ver arriba, nota 14.

${ }^{30}$ Rickert, GE, p. 9.

Manuscrito - Rev. Int. Fil., Campinas, v. 37, n.2, pp. 357-413, jul.-dez. 2014. 
comprender que el psicologismo se funda en una idea falsa de subjetividad y que, correlativamente, solo puede ser refutado si se abandona ésta. Frege, no obstante, es el primero que identifica la falsedad de esta idea de subjetividad como reposando, en última instancia, en el PI. Pero, se nos dirá, ¿no fue la revisión del PI iniciada en la escuela de Brentano y, más concretamente, por Twardowsky? Otra vez: obsérvese que recién ahora deviene comprensible porque, dado nuestro propósito, era tan importante establecer un contexto de discusión en el cual Twardowsky fuera considerado. El punto central es que el famoso artículo de Twardowsky es de 1894; inequívocamente, sin embargo, Frege establece como eje de su crítica del psicologismo el PI a partir de 1893, en el prefacio a las "Leyes fundamentales de la aritmética", o sea, un año antes ${ }^{31}$.

${ }^{31}$ Para entender la importancia del hecho de que Frege abandona el PI en 1893 se debe atender a su contexto histórico, el cual no queda suficientemente delineado si solo se considera la escuela de Brentano. En torno a esa fecha las relaciones entre inmanencia y transcendencia se convierten en tema central de la teoría del conocimiento. En tal sentido conviene recordar cinco elementos: a. En estos años toma cuerpo la Immanensphilosophie, cuyo principal representante es Wilhelm Schuppe, quien junto con M. R. Kauffman y R. Schubert-Söldier, funda en el año 1895 el Zeitschrift für Immanensphilosophie, que será publicado hasta 1897.

b. La Immanensphilosophie hizo parte de un movimiento más amplio que fue integrado por el empiriocriticismo de Mach y Avenarius; entre ambas escuelas existió un mutuo reconocimiento de los puntos de contacto.

c. La consolidación de la Immanenspphilosophie provocó una reacción realista y llevó a una abierta polémica que se prolongó en la década siguiente. (Las informaciones sobre Immanensphilosophie en a. b. y c. están extraídas del artículo correspondiente de Ritter, 1976, p. 238)

d. Un importante elemento para reconstruir este período lo ofrece el informe natorpiano sobre la situación de la teoría del conocimiento entre los años

Manuscrito - Rev. Int. Fil., Campinas, v. 37, n.2, pp. 357-413, jul.-dez. 2014. 
5. Mas, la razón por la cual la crítica fregueana al PI tiene que ser situada en relación con la escuela de Brentano no se limita a una prioridad cronológica de un año (lo cual, por otra parte, es en sí de extrema importancia y no debe ser en modo alguno menospreciado). Para entender por qué el establecer la relación de Frege con la escuela de Brentano es relevante, tenemos que considerar la crítica fregueana al psicologismo en la segunda perspectiva indicada, a saber, en la genético-evolutiva.

a. Aun cuando la crítica al psicologismo es una constante en el pensamiento fregueano, ella va experimentando importantes variaciones. Así, en un cierto sentido podemos decir que Frege ya era antipsicologista en la "Conceptografia" y probar tal tesis mostrando pasajes en donde él claramente distingue entre questio facti y questio iuris ${ }^{32}$. No obstante (y, lo que es más decisivo), podemos mostrar otros en donde Frege considera que representaciones son el significado de conceptos, o que reunión de representaciones son el significado de juicios, tesis estas que posteriormente combatirá con vehemencia ${ }^{33} . \mathrm{Si}$ pasamos ahora a "Los fundamentos de la aritmética" vemos que tales equívocos son eliminados y que, de hecho, Frege presupone la negación del $\mathrm{PI}^{34}$ sin que, no obstante, la convierta en el eje de su crítica al psicologismo, concentrada por el contrario en la distinción entre objetivo y real. Esto acontece, como ya fue indicado, por primera vez en el prefacio de las "Leyes fundamentales de la aritmética".

1894-1895, el cual, no por casualidad, comienza con Schuppe y considera entre otros a Twardowsky.

e. A este contexto pertenece también "Der Gegenstand der Erkenntnis" de Rickert, razón por la cual hemos citado esta obra en su primera edición de 1892.

32 Beg, p. IX.

${ }^{33}$ Beg, pp. 2 y 10 y $15-16$.

34 GA, $\$ 93$, p. 96.

Manuscrito - Rev. Int. Fil., Campinas, v. 37, n.2, pp. 357-413, jul.-dez. 2014. 
b. "Los fundamentos de la aritmética" fueron publicados en 1884, las "Leyes fundamentales de la aritmética", en 1893. Estoy convencido de que las mudanzas que pueden ser constatadas en la crítica fregueana al psicologismo entre 1884 y 1893 tienen que ver con las reacciones que ella enfrenta. Sabidamente, Husserl efectúa en su "Filosofia de la aritmética" (1891) una dura crítica a "Los fundamentos de la aritmética”, crítica que desencadenará la reacción de Frege en su reseña de esta obra. En general, se insiste por parte de los simpatizantes de Husserl en subrayar que la crítica fregueana es injusta, pues simplifica y superficializa la posición del oponente ${ }^{35}$. No voy a entrar aquí en esta discusión pero sí indicar que, frente a la imponente literatura apologética husserliana, conviene no olvidar que Husserl no meramente critica la concepción fregueana del número, sino que no tiene ninguna consideración por la crítica de Frege al psicologismo en "Los fundamentos de la aritmética", sino que abiertamente la desconsidera ${ }^{36}$. Esto es lo que en parte explica la virulenta y, en tal sentido, justa crítica fregueana. Husserl mismo concede su error en las "Investigaciones lógicas" 37 , además de en la famosa entrevista a Gibbson ${ }^{38}$. Sea dicho de paso que en la "Filosofía de la aritmética" Husserl es aún un defensor expreso del PI y, por tanto, sin duda un psicologista en el sentido de Frege ${ }^{39}$.

c. Ahora, la relevancia de la perspectiva indicada se confirma si atendemos a otro hecho. Husserl no es el único que, de las filas de la escuela de Brentano y su método psicológico, reacciona con indiferencia a la crítica de Frege al psicologismo. También en Kerry

\footnotetext{
35 Mohanty (1982), Ortiz (1991), Tieszen (1994), Drummond (1985) y Rosado Haddock (2006).

${ }^{36}$ Hua, XII, p. 118-119.

${ }^{37}$ Hua, XVIII, p. 172.

${ }^{38}$ Hua, XVIII, p. XXIII.

${ }^{39}$ Hua, XII, p. 80.
}

Manuscrito - Rev. Int. Fil., Campinas, v. 37, n.2, pp. 357-413, jul.-dez. 2014. 
encuentra Frege una similar reacción e, incluso, mucho más radical. En un pasaje decisivo de "Sobre intuición y su procesamiento psíquico" de 1887, Kerry escribe que Frege no solo no tiene un concepto claro de lógica, sino que padece, por un lado, de horror subjectivi, pues ha visto un problema que no existe, el psicologismo, y, por otro, no ve o pasa por alto el verdadero problema, a saber, cómo es posible que lo objetivo surja de lo subjetivo, verdadero problema que es ineludible dado que, al fin de cuentas, todo nuestro conocimiento necesariamente tiene que partir de lo subjetivo ${ }^{40}$. Obviamente, en la base de la argumentación de Kerry se encuentra presupuesto el PI.

d. Frege debe haber quedado muy sorprendido de que alguien pudiera poner en duda, no ya su concepto de lógica, sino la justicia e inclusive la importancia de su crítica al psicologismo y, más aún, que no solo una, sino dos de las pocas reacciones a los "Fundamentos de la aritmética" fueran en la misma dirección. Es esto lo que explica el hecho de que él vuelva en "Leyes fundamentales de la aritmética" no solo a esa crítica, sino que lo haga de un modo más incisivo que hasta entonces. Lo que llama la atención en "Leyes fundamentales de la aritmética", diferenciando radicalmente esta obra de "Fundamentos de la aritmética" en lo que dice respecto a la crítica al psicologismo, es que si en la última, la distinción entre objetivo y real parece establecer un punto final, en la primera ella no representa sino un momento que, a su vez, es remitido a una diferencia más fundamental, a saber, el ya referido PI, el cual ahora es situado como presupuesto último sobre el cual reposa el desvarío psicologista ${ }^{41}$. Más, si no bastase la clara profundización lógico-sistemática que, de hecho, acontece en el

\footnotetext{
40 ÜAPsV, IV, p. 305. Un detallado análisis de la crítica de Kerry, así como del papel de Husserl en este contexto, se encuentra en González Porta, Horror subjectivi.

41 Para una reconstrucción del argumento fregueano, véase González Porta, 2012, p. 111-112.
}

Manuscrito - Rev. Int. Fil., Campinas, v. 37, n.2, pp. 357-413, jul.-dez. 2014. 
proceder argumentativo de "Leyes fundamentales de la aritmética" con respecto a "Fundamentos de la aritmética", existen manifestaciones expresas de Frege que adquieren pleno sentido si se tiene en cuenta la objeción de Kerry. Así, en tanto que Kerry criticaba a Frege por no tener un concepto claro de lógica, Frege escribe que su propósito es clarificar su idea de lógica mediante contraposición a la de su oponente ${ }^{42}$; frente a la ironía de Kerry de que Frege padece de horror subjetivi, él explícitamente manifiesta (haciendo uso de una conocida imagen de "Don Quijote de la Mancha"), que su objetivo es mostrar que no lucha contra "molinos de viento" $43 \mathrm{y}$, finalmente, frente a la pretendida improcedencia del peligro de relativismo, Frege se concentra en evidenciar que el mantenimiento del PI necesariamente conduce al solipsismo ${ }^{44}$. Más aún, si se tiene en cuenta la crítica de Kerry, resulta plenamente comprensible, porque Frege, contra su costumbre, procura fundar su tesis en generosas citas del partido opositor y, más aún porque elige aplicar esta estrategia a Erdmann ${ }^{45}$, pues en este está explícito y manifiesto por extenso lo que, en el propio texto de Kerry aparece de modo fugaz y como presupuesto que, por su obviedad, no merece mayor consideración.

e. Si se atiende a la crítica de Kerry, no solo puede leerse sobre una nueva luz el prefacio de las "Leyes fundamentales de la aritmética", sino que otros textos, que justamente son una y otra vez citados como pruebas irrecusables de que Frege no tiene ningún interés por la cuestión de la subjetividad, remitiendo ésta a la psicología, adquieren un nuevo sentido. En efecto, en la "Lógica" de 1897, aun cuando sin citarlo, Frege establece una objeción similar a aquella que fuera

\footnotetext{
${ }^{42} \mathrm{GGA}$, p. XXV.

43 GGA, p. XIX.

44 GGA, p. XIX.

45 GGA, p. XIXss.
}

Manuscrito - Rev. Int. Fil., Campinas, v. 37, n.2, pp. 357-413, jul.-dez. 2014. 
realizada por Kerry ${ }^{46}$ : el pensamiento puede ser tan objetivo como se quiera, no obstante, su aprehensión es un proceso subjetivo y, por tanto, psicológico. Obviamente que, para que aquí se contenga una objeción a la línea de pensamiento que Frege ha desenvuelto anteriormente en el texto mencionado, tiene que presuponerse la validez del PI. Es esto lo que hacía Kerry, como ya mucho antes Exner.

\section{La concepción fregueana de subjetividad}

1. En el presente numeral me propongo aportar elementos en el sentido de mostrar que Frege posee una "concepción de subjetividad". Esto, ciertamente, no es en modo alguno obvio y, para muchos, simplemente una herejía. Más, si se atiende al hecho de que Frege focaliza su crítica al psicologismo en la crítica de la concepción psicologista de subjetividad, tal tesis comienza a ser plausible. En realidad, crítica al psicologismo, o sea, a la concepción psicologista de subjetividad, y propuesta de una concepción alternativa no son opuestos y excluyentes, sino complementarios. Aquellos que, de la radical crítica fregueana al psicologismo creen poder derivar una indiferencia absoluta de Frege con respecto a la subjetividad, simplemente no han entendido esta crítica, posiblemente porque tampoco han percibido su novedad ${ }^{47}$.

2. La concepción fregueana de la subjetividad contiene un principio fundamental, que puede ser expresado tanto de un modo negativo, cuanto de un modo positivo. Expresado de modo negativo, se trata del ya tantas veces mencionado rechazo radical del PI. Expresado

\footnotetext{
${ }^{46} \mathrm{~L}$ (1897), p. 63-64.

47 Véase Bell, 1994, p. 190. No son pocos los textos en que el análisis de la crítica fregueana al psicologismo en "Leyes fundamentales de la aritmética" ni siquiera mencionan aquello que es a todas luces el punto esencial. Tal es el caso de Rosado Haddock (2006, p. 110-114).
}

Manuscrito - Rev. Int. Fil., Campinas, v. 37, n.2, pp. 357-413, jul.-dez. 2014. 
positivamente se trata de la tesis de que el sujeto es capaz de captar de modo directo e inmediato objetos que no meramente no son contenidos de su conciencia (Bewusstseinsinhalte), sino que tampoco devienen tales por el hecho de ser captados ${ }^{48}$. Dicho de otra forma: la negación del PI implica la negación de todo representacionalismo. El contenido de la conciencia es tan solo el medio a través del cual la conciencia se dirige a algo que no es su contenido. A través de algo que es real en la conciencia, somos capaces de dirigirnos a algo que no es real en ella ${ }^{49}$ ni deviene real en ella en sentido alguno por el hecho de

${ }^{48}$ GGA, pp. XVIII, XX, XXI, XXII y XXIV; L (1897), pp. 41, 46, 51, 62 y 69; G, pp. 45 (70), 50 (75), 49 (73), 42 (68) y 46-47 (71-72); LM, p. 102. Hemos citado profusamente y en orden cronológico los textos centrales de Frege para nuestro tema no sin razón. Es una opinión ampliamente difundida que "Der Gedanke" es una obra atípica. Este es un refugio usual de los críticos cuando se evidencia en los textos las manifestaciones de Frege con respecto a la idea de subjetividad. Por eso es importante mostrar, que ideas similares ya se encuentran en obras anteriores. En realidad, "Der Gedanke", y las "Logische Untersuchungen" en general, son la culminación de una serie de intentos de Frege por escribir una lógica que, comenzando con el prefacio de GGA, se extienden por la "Logik" de 1879-1891, la de 1897, los "17 Kernsätze" y la "Einleitung in die Logik". En todos esos trabajos hay un padrón temático y "tético" de lo que Frege considera esencial a los efectos de una fundamentación de la disciplina. En tal sentido, es importante observar, que aun cuando Frege remite a la psicología la cuestión de la captación del pensamiento, en todas esas obras, las consideraciones respecto de la subjetividad hacen parte esencial de los temas a ser abordados. En suma, todas las tesis sustentadas por Frege en 1918 encuentran correlatos, sino idénticos, al menos muy aproximados, en los textos anteriores. La verdadera novedad de "Der Gedanke" es que por primera vez Frege se propone una prueba de su negación del PI, en vez de simplemente postularla como hasta entonces (prueba que, erróneamente, es confundida con el problema cartesiano de la demostración de la existencia de una realidad externa). Véase González Porta, 2009.

${ }^{49} \mathrm{G}$, p. 50 (75).

Manuscrito - Rev. Int. Fil., Campinas, v. 37, n.2, pp. 357-413, jul.-dez. 2014. 
ser captado. Sin esta nuestra capacidad, "se rompe todo puente a lo objetivo" 50 .

3. Una vez analizada la postura fregueana con respecto al PI, alguien podría objetar que esto es muy poco para afirmar que allí se encuentra una "concepción de subjetividad" y que incurrimos en no otra cosa que una exageración. Podemos responder a tal objeción de dos formas.

a. La primera es que, aun cuando Frege se limitase a negar el PI, quien comprende: primero, la importancia que ese principio posee en el pensamiento moderno; segundo, la intensa adhesión al mismo por los filósofos alemanes en el contexto de la crítica a Hegel; tercero, la importancia de su revisión a través de un complicado proceso en la escuela de Brentano desencadenado por Twardowsky y cuarto, el hecho de que Frege está abordando un punto neurálgico de la discusión epistemológica de su tiempo, difícilmente podrá dejar de ver que, aun cuando las manifestaciones fregueanas con respecto a la subjetividad sean escasas, la importancia de esa única tesis es de por sí decisiva. Frege está nada más y nada menos que rompiendo de modo radical con la tradición cartesiana. Si Frege es plenamente consciente de la relevancia de su tesis, esto es otra cuestión, y una tal que puede dejar margen a dudas. Es probable que Frege se distancie de la tendencia dominante porque recepciona sin reservas la línea heterodoxa iniciada por Reid ${ }^{51}$ y que probablemente le llega, vía Hamilton, a través de Stuart Mill. En realidad, Stuart Mill es una de las fuentes decisivas del antipsicologismo fregueano ${ }^{52}$ y un elemento fundamental para dar a

\footnotetext{
${ }^{50} \mathrm{~L}$ (1897), p. 62.

51 EIPM, II, 14, p. 211-212.

52 Mill: Logic, Book I, Chapter II. Véase también Chapter V. Cfe. Skorupski, 1989 y 1998.
}

Manuscrito - Rev. Int. Fil., Campinas, v. 37, n.2, pp. 357-413, jul.-dez. 2014. 
este su forma característica a través de la distinción entre sentido y referencia ${ }^{53}$.

b. Pero, para quien no quiera convencerse con el argumento anterior (que a mi ver, insisto, es por sí mismo decisivo), entonces podemos indicar que nuestra tesis no se basa exclusivamente en el hecho de que Frege niega el PI, sino en que efectúa un conjunto de afirmaciones que, derivándose de tal negación, van más allá de ella y la desenvuelven. De la negación del PI Frege deriva una teoría del pensar, del juzgar, del percibir, del decidir y del yo. Analizamos las mismas en los parágrafos siguientes (5-18).

4. Para Frege el pensar (denken) es aprehensión de pensamientos (Fassen von Gedanken $)^{54}$. Esta importante tesis fregueana, que establece nuevas coordenadas para una definición del pensar, tiende a ser trivializada, simplemente porque se desconoce el contexto de la misma y, por tanto, su novedad. Que pensar es aprehensión de pensamientos significa dos cosas: por un lado, la acentuación francamente realista del carácter receptivo-pasivo del pensar frente a toda teoría de la síntesis ${ }^{55}$; por otro, la negación de que el mismo pueda ser reducido a un tipo particular de síntesis, a saber, la asociación de representaciones ${ }^{56}$. Dicho de otra forma, la concepción fregueana de pensamiento se opone por igual al idealismo transcendental y a cualquier compromiso entre empirismo e idealismo naturalista, algo muy común en su época.

${ }^{53}$ En tanto esto implica combatir por igual el psicologismo de la significación ideal (Sinn) y el psicologismo del objeto (ideal o real) (Bedeutung).

${ }^{54}$ L (1897), p. 37 . Cfe. L (1897), p. 51-52; G, p. 35 (62) y pp. 49-50 (74); EL, p.

74. Sobre la explicación del sentido de la imagen del Fassen, véase L, (1897), p.

52 y G, p. 49n (74n).

${ }^{55} \mathrm{~L}$ (1897), pp. 35, $42-43$ y 63.

${ }^{56} \mathrm{~L}$ (1897), p. 64n.

Manuscrito - Rev. Int. Fil., Campinas, v. 37, n.2, pp. 357-413, jul.-dez. 2014. 
5. Mas, se podrá decir que la tesis que ahora nos ocupa no tiene ninguna relevancia desde el punto de vista teórico-subjetivo, siendo tan solo una consecuencia del platonismo fregueano, o sea que, en última instancia, Frege está únicamente interesado en afirmar la existencia de objetos lógicos y, eventualmente, idealidades de otros tipos. Por eso es importante subrayar: la tesis de que pensar es captar pensamientos no es meramente un corolario de la postulación de objetos lógicos, sino una tesis específica respecto a la subjetividad. Decir que existe algo objetivo-irreal y decir que puedo aprehenderlo (y, más aun, que puedo aprehenderlo sin que por ello devenga real en mî) son dos tesis esencialmente diferentes. Para percibir lo anterior, observemos que Frege establece su tesis a través de la explícita y consciente crítica a concepciones rivales, en parte empiristas-asociacionistas, pero en parte también platónicas. Con respecto al primer punto debe llamarse la atención sobre la nota a pie de página en el famoso pasaje de la "Lógica" de 189757. Con respecto al segundo punto, conviene comparar a Frege con Bolzano sistemáticamente, por un lado y, con Lotze históricamente, por el otro. La relación de Frege con Lotze es de particular interés porque, sobre la base de coincidencias importantes, se establece no obstante una diferencia decisiva. Frege coincide con Lotze en el hecho de que existe algo objetivo y no-real, así como en el hecho de que lo captamos; diverge, no obstante, en la explicación de cómo lo captamos. Lotze se mantiene fiel al PI y considera que todos nuestros objetos, en última instancia, necesariamente son nuestras representaciones ${ }^{58}$. Como consecuencia de tal presupuesto, él tiene que explicar el pensar a partir de representaciones y lo hace diciendo que lo que diferencia un juicio de una mera asociación es que en él hay un pensamiento complementario (Nebengedanke) que proporciona la justificación de la unión ${ }^{59}$. A esta solución se opone expresamente

\footnotetext{
57 Véase nota anterior.

58 Véase nota 27.

${ }^{59}$ L, III, p. 5 e VIII, p. 9.

Manuscrito - Rev. Int. Fil., Campinas, v. 37, n.2, pp. 357-413, jul.-dez. 2014.
} 
Frege con la tesis que analizamos, insistiendo en que el pensamiento no versa jamás sobre representaciones, sino sobre objetos y conceptos ${ }^{60}$.

6. Frege distingue claramente entre pensar y juzgar, o sea, entre la mera captación del pensamiento o aprehensión de un sentido y la atribución al mismo de un valor de verdad ${ }^{61}$. Esta distinción reafirma su rechazo de toda teoría de la síntesis con su denuncia de la confusión entre síntesis y afirmación. Ni el pensar ni el juzgar pueden ser síntesis de representaciones.

7. En repetidas ocasiones Frege define de modo idéntico el pensar como el captar pensamientos. Algo un tanto diferente ocurre con respecto al juzgar. Mayoritariamente Frege define el juzgar como un reconocimiento de la verdad (Anerkennung der Wahrheit) ${ }^{62}$. Esta definición no deja de contener problemas, pues parece excluir de principio la posibilidad del juicio falso. En tal sentido, la expresión "tener por verdadero" (Fürwabrhalten) ${ }^{63}$ (muy usada por Frege en general, pero poco usada en el contexto de una definición del juicio) parece más adecuada, pues ella contempla la posibilidad de que ese "tener por verdadero" sea erróneo, algo que, de un modo puramente analítico, la expresión "reconocimiento de la verdad" (Anerkennung) parece excluir. De todas formas, existen algunas ocasiones en las que Frege ofrece una definición a todas luces más apropiada del juicio, tal que excluye toda dificultad con respecto al juicio falso ${ }^{64}$. En este caso el juicio es definido como una elección ( $W$ ahb) entre valores de verdad,

${ }^{60}$ L (1897), p.23. Compárese Dummett, 1998, p. 65ss.

${ }^{61} \mathrm{G}$, p. 35 (62); L (1897), p. 54; EL, p. 201.

62 Además de los textos ofrecidos en nota anterior, véase GG, p. 73-74.

${ }^{63} \mathrm{~L}$ (1897), p. 38-39.

$64 \mathrm{~V}$, p. 63.

Manuscrito - Rev. Int. Fil., Campinas, v. 37, n.2, pp. 357-413, jul.-dez. 2014. 
los cuales obviamente son opuestos excluyentes, de forma tal que el rechazo del uno implica la aceptación del otro ${ }^{65}$.

8. La teoría fregueana de la percepción se opone a todo sensualismo sobre la base de que este confunde el tener impresiones sensibles con el percibir objetos. La presencia de impresiones sensibles en la conciencia es una condición necesaria pero no suficiente de la percepción. La percepción de un objeto supone, además de contenidos sensibles, la captación de algo no-sensible. Lo que nos abre las puertas del mundo externo no son las impresiones sensibles, en sí mismas privadas, sino nuestra capacidad de captar algo no sensible y, no obstante, plenamente objetivo $^{66}$.

9. Pero, según Frege, para tener una percepción de x no basta con captar el correspondiente pensamiento $\mathrm{x}$, sino que tenemos que ir más allá y efectuar un juicio. La distinción entre el pensar y el juzgar está, pues, contenida en la teoría de la percepción y se integra con ella ${ }^{67}$.

10. Ya que la percepción se compone de tres elementos heterogéneos (el tener una impresión sensible, el captar un pensamiento y el juzgar), debemos preguntar: ¿cómo se interrelacionan concretamente estos elementos? El punto principal parece ser el siguiente: si bien es cierto que, en principio, para la captación de un pensamiento precisamos un elemento sensible, la impresión sensible que poseemos en la percepción no es pensada en función del rol que juega en la captación del

\footnotetext{
${ }^{65}$ EL, p. 74. Compárese también V, p. 55.

${ }^{66}$ G, pp. 34 (61) y 50-51 (75). Esta no es la primera vez, como dice Prauss (1976, p. 39n.), que Frege se ocupa de la percepción. Ya lo hizo, y en igual dirección, en ocasiones anteriores (GA, §27, p. 42; L (1897), p. 53).

${ }^{67}$ L (1897), p. 149.

Manuscrito - Rev. Int. Fil., Campinas, v. 37, n.2, pp. 357-413, jul.-dez. 2014.
} 
pensamiento, sino como un factor decisivo en la motivación del juicio ${ }^{68}$.

11. Frege posee una teoría de las decisiones (Entschlüsse). Existe un curioso texto, que hasta ahora ha sido pasado por alto por los comentadores, o que, en la única ocasión que ha sido observado, también ha sido erróneamente interpretado ${ }^{69}$. En él Frege observa que las decisiones no son representaciones; más precisamente, que el concepto de representación incluye impresiones sensibles, creaciones de la fantasía, sensaciones, sentimientos, estados de ánimo, tendencias y deseos, pero no decisiones ${ }^{70}$. La consecuencia fundamental que se deriva de lo anterior es que, entonces, no todo aquello que normalmente llamamos "psíquico" es una representación o se reduce a una representación ${ }^{71}$. Ahora, la pregunta obvia que surge frente al texto referido es: ¿por qué decisiones no son representaciones? La respuesta es más simple de lo que podría esperarse. Dado que Frege afirma expresamente que las representaciones son aquello que está sometido a las leyes de la asociación $n^{72}$, la consecuencia obvia es que las decisiones

${ }^{68}$ LA, p.167; EQ, p. 286.

${ }^{69}$ Künne, 2010, p. 490ss.

${ }^{70}$ G, p. 39 (66). Veáse, en las líneas a continuación, cómo Frege mantiene la distinción entre Vorstellung y Entschluss (G, p. 40 (67)). Representaciones (Vorstellungen) y decisiones (Entscblüsse) actúan como las dos posibilidades de algo presente en el mundo interno (Innenwelt) (G, p. 41 (67)), o sea: decisiones (Entscblïsse) no son „tenidas“ (werden gehabt). Se podría preguntar si, además de las decisiones (Entschlïsse), también el pensar (denken) y el juzgar (Urteilen) son "tenidos". Más bien, ellos parecen ser "actos", que se basan en algo que es tenido, pero que no se reducen a él. Hay un momento "activo" en la subjetividad, que no se reduce al tener representaciones y del cual las decisiones sean tal vez su núcleo o momento más expresivo.

71 Existe una marcada tendencia a identificar en Frege la noción de representación y psiquismo (así en Mohanty, 1989, pp. 3-4 y en Bégout, 2002, p. 127).

72 GA, \$27, p. 41-42.

Manuscrito - Rev. Int. Fil., Campinas, v. 37, n.2, pp. 357-413, jul.-dez. 2014. 
no son representaciones porque no están sometidas a las leyes de la asociación. Si volvemos a preguntar por qué no lo están, ya no es posible encontrar una respuesta expresa en un texto de Frege, pero tampoco es difícil descubrir cuál sería esta: si las decisiones estuvieran sometidas a las leyes de la asociación, entonces las mismas estarían determinadas, o sea, la idea de decisiones libres $y$, eventualmente, racionales, perdería sentido.

12. Los juicios, como sabemos, suponen, además de la captación de pensamientos, una elección de valor de verdad, o sea, ellos son un tipo de decisiones. Este hecho merece una atención especial.

13. Obsérvese que la mera negación del PI por sí sola no asegura la posibilidad del juicio. Vimos (4 (8)) que Frege diferencia expresamente entre el tener representaciones (Haben von Vorstellungen) y el ver cosas (Sehen von Dingen). Podemos tomar esta oposición como base de otra, a saber, entre el "tener representaciones" y el "efectuar acciones". En tal sentido, representaciones son "tenidas"; decisiones, sin embargo, de las cuales los juicios constituyen un caso particular, no son tenidas, sino "efectuadas" (activamente). Habría pues una doble razón por la cual las decisiones no son representaciones, a saber: ellas no meramente no están sometidas a las leyes de la asociación, sino que tampoco son propiamente "tenidas", sino "efectuadas"73. Ahora, si consideramos que los juicios son un tipo de decisiones, debemos tener cuidado en considerar "actividad" sin más como sinónimo de "espontaneidad", con todas las implicaciones idealistas de esta noción ${ }^{74}$.

\footnotetext{
73 Obsérvese que ambas características están intrínsecamente vinculadas.

74 Esto es importante para situar adecuadamente el estatus ontológico del pensar en Frege, problema que preocupa a Bégout (2002, p. 129). El pensar es pasivo con respecto a lo pensado, pero él no es simplemente "tenido" como una representación.
}

Manuscrito - Rev. Int. Fil., Campinas, v. 37, n.2, pp. 357-413, jul.-dez. 2014. 
14. Lo anterior parece ir contra la idea, indudablemente fregueana, de que la psicología se ocupa del establecimiento de leyes naturales, lo cual, a su vez, es coherente con el modo que trata el juicio ${ }^{75}$. Pero tal vez Frege no diga meramente esto. En efecto, Frege observa que es posible que en la determinación de procesos psíquicos estén presentes leyes lógicas ${ }^{76}$. ¿En qué sentido? Al menos es pensable en dos, a saber, o bien el mecanismo natural produce resultados condicentes con las leyes lógicas ${ }^{77} \mathrm{O}$ bien el conocimiento de las leyes lógicas es un factor actuante en el proceso psíquico. El hecho de que Frege no diga que el proceso psíquico es conforme a las leyes lógicas, sino que las leyes lógicas toman parte en él, me inclina a la segunda opción. Que el "tener por verdadero" (Fürwahrbalten), de hecho, también esté determinado por leyes no-lógicas, no excluye, pues, en principio, la posibilidad de que, en casos peculiares, también sea determinado únicamente por estas y, por tanto, de ello no se puede sacar nunca la conclusión de que siempre está determinado por factores causales extra-lógicos y, eventualmente, asociativos. Aun cuando Frege remite el problema del juicio a la psicología, él deja abierta esta posibilidad. Además, ¿por qué el pensar, el juzgar y el inferir no podrían estar "motivados" por factores intencionales, cuando la decisión, contenida en los dos últimos, lo está?

\footnotetext{
75 El único ejemplo que Frege ofrece acerca de qué pueda ser una ley del "tener por verdadero" se encuentra en la "Lógica" de 1879-1891 (p. 2-3). Según ella, los casos confirmatorios ejercen mayor efecto que los refutadores. En este texto es interesante observar que la ley del "tener por verdadero" no es meramente una ley asociativa, sino que tendría eventualmente más que ver con lo que llamaríamos desde un punto de vista moderno un condicionamiento operante.

${ }^{76} \mathrm{G}$, p. 30-31 (59).

77 Esta idea puede ser encontrada en Windelband en el tratamiento de la relación realidad-valor (González Porta, 1989, p. 30-34).
}

Manuscrito - Rev. Int. Fil., Campinas, v. 37, n.2, pp. 357-413, jul.-dez. 2014. 
15. Las decisiones (Entschlüsse) no son algo así como mónadas en la mónada; ellas no están desvinculadas de otros momentos del psiquismo; están vinculadas, no obstante, de un modo intencional y no mecánico-causal ${ }^{78}$. Los pensamientos (Gedanken) no pueden "producir" (wirken) otra cosa que un saber (Kenntnis), el cual "motiva" nuestras decisiones (Entschlüsse) o actúa sobre ellas.

16. Un elemento importante para percibir que en Frege hay un interés por la relación objetividad-subjetividad se encuentra en el hecho de que él aborda esta relación en una doble dirección, o sea, tanto en aquella que va de lo subjetivo a lo objetivo, cuanto, inversamente, en aquella que va de lo objetivo (más concretamente del pensamiento) a lo subjetivo. Es esto justamente lo que ocurre en un aparentemente extraño texto de esa obra pretendidamente atípica, "Der Gedanke"79. Pues bien, fuera del hecho de que esto podría ser interpretado como una evidencia más de un interés fregueano que no desaparece en sus últimos años, debe observarse que, lo que a primera vista puede parecer una teoría propia de un "naturalismo metafísico", a saber, la extraña idea de una "acción causal de pensamientos" (Wirken von Gedanken), cuando es analizado, se evidencia, en última instancia, como coherente con una postura intencional ${ }^{80}$. Aquellos que aíslan el mencionado pasaje de "Der Gedanke" olvidan que consideraciones muy similares ya están presentes en la "Lógica" de 1897, y de un modo incluso mucho más claro en lo que dice a las verdaderas intenciones de Frege, a saber,

\footnotetext{
${ }^{78} \mathrm{~L}$ (1897), p. 53.

${ }^{79} \mathrm{El}$ análisis usual de este texto es ofrecido por Currie (1980, 1982). Otra interpretación ofrece González Porta, 2013.

80 Sobre intencionalidad en Frege véase más abajo 6 (2).
}

Manuscrito - Rev. Int. Fil., Campinas, v. 37, n.2, pp. 357-413, jul.-dez. 2014. 
sobre la importante salvaguarda de que una consideración literal de la cuestión propuesta solo puede llevar a una mitología ${ }^{81}$.

17. El último punto que debe ser destacado en la concepción fregueana de subjetividad es el referente a la negación de la tesis de que el yo se deje reducir a una representación $o$ a un conjunto de representaciones ${ }^{82}$, así como la afirmación de que la propia existencia del yo (el fenómeno de la autoconciencia) evidencia que es falsa la idea de que solo me son dados como objetos mis contenidos inmanentes ${ }^{83}$. Al menos puedo captar mi propio yo y este no se deja reducir a un contenido de conciencia.

18. Efectuemos una mirada retrospectiva sobre la concepción fregueana de la subjetividad. En principio nunca puede dejarse de lado el hecho de que Frege no posee propiamente una "teoría de la subjetividad" en el sentido de una doctrina central y plenamente desarrollada, sino que se limita a efectuar señalamientos en la dirección de una "concepción de subjetividad". Tampoco puede dejarse de lado que estos señalamientos no responden a todas las preguntas que ellos mismos sugieren, dejando abiertas muchas interrogantes. No obstante lo anterior, no puede pasarse por alto el hecho de que los diferentes señalamientos fregueanos no son inconexos, sino que se complementan, resultando en un todo unitario y coherente y, que, en última instancia, se fundan en un claro núcleo común. Lo que Frege dice sobre el pensamiento se integra con lo que él dice sobre el juicio, y

${ }^{81}$ L (1897), p. 52-53. Un análisis detallado del tema ofrece González Porta, 2012.

${ }^{82}$ G, p. 46-47 (71). Es probable que Frege esté tomando como referencia crítica "Die Analyse der Empfindung" de Mach (Véase Picardi, 1996, p. 325326). Si esto es cierto, el hecho de Frege estar conscientemente polemizando no deja de ser digno de destaque, pues anula toda posibilidad de disminuir la importancia de estos textos considerándolos meramente aleatorios.

${ }^{83} \mathrm{G}$, p. 47 (71).

Manuscrito - Rev. Int. Fil., Campinas, v. 37, n.2, pp. 357-413, jul.-dez. 2014. 
esto, a su vez, lo hace con lo que dice sobre la percepción; así como lo que dice sobre las decisiones (Entschlïsse) se integra con lo que dice sobre el juicio y esto, a su vez, lo hace con lo que dice sobre el yo. Asimismo, lo que Frege dice con respecto al sustrato sensible en relación a la percepción se integra con lo que él dice respecto al sustrato del pensamiento, no menos que con lo que él afirma en general sobre la relación con el objeto. En todos los casos, el principio básico es que hay algo de real en la conciencia, que es condición de la referencia al objeto, pero que no debe ser confundido con esta misma referencia, siendo que este principio básico va siendo aplicado a diferentes niveles, a saber, al sujeto en general, a la percepción, al pensamiento, etc. ${ }^{84}$.

\section{Revisión de la visión standard de Frege}

1. Existe algo así como una lectura standard de Frege en relación a su interés por cuestiones relativas a la subjetividad ${ }^{85}$. Esta lectura es defendida por representantes de dos partidos diametralmente opuestos, a saber, tanto por analíticos ortodoxos ${ }^{86}$ cuanto por defensores de la

${ }^{84}$ Con respecto a la percepción: G, pp. 40-41 (67) y 50-51 (75); con respecto al pensamiento: $G$, p. 49 (74). En algunas ocasiones vincula ambas distinciones en un único sistema conceptual como en G, p. 44n (70n) y p. 49-50 (74).

${ }^{85}$ La figura más representativa de lo que llamamos la "visión standard" es sin duda Mohanty (1977, 1982, 1989, 2003). Con variaciones, a veces significativas, ideas similares son usuales en muchos otros autores como, por ejemplo, en Dallas Willard (1977, 1994), Barry Smith (1978, 1994), David Bell (1979, 1994), Henning Peucker (2002) y Bruce Bégout (2002), entre otros.

86 Compárese Schulte, 1984, p. 71. Por regla general los lectores analíticos tienden a subrayar unilateralmente todo aquello que Frege dice respecto de una semántica o filosofía del lenguaje, desconociendo otros aspectos. Así acontece a partir de la línea dominante establecida por Dummett, quien, no obstante, como gran conocedor de Frege, no descuida análisis minuciosos de los textos y ha tendido a matizar su posición. A modo de ejemplo de meticulosidad en el manejo de los textos y perspectiva prefijada véase Dummett, 1990, p. 73. Ciertamente, para quien ve en Frege únicamente la virada al lenguaje como

Manuscrito - Rev. Int. Fil., Campinas, v. 37, n.2, pp. 357-413, jul.-dez. 2014. 
fenomenología ${ }^{87}$. Lo que mueve a ambos es, sin embargo, totalmente diferente. Los primeros quieren ver en Frege el héroe de la virada semántica, cuando no un puro filósofo de las matemáticas; los segundos desean evidenciar la superioridad del proceder de Husserl sobre el de Frege, en cuanto él realiza una pregunta legítima y la trata por extenso, para la cual Frege no poseería ni sensibilidad ni comprensión.

2. La lectura standard se resume básicamente en dos tesis, a las cuales a menudo se les suman otras dos.

Ta. El problema de la aprehensión del pensamiento es remitido por Frege a la psicología.

Tb. De esto se extrae la consecuencia de que Frege no posee ningún interés por la cuestión de la subjetividad.

Sobre la base de las dos primeras tesis puede tomarse ahora dos caminos diferentes, a saber, o permanecer en la tesis $\mathrm{Tb}$ y simplemente afirmar que Frege no dice absolutamente nada con respecto a la subjetividad, o se puede observar

camino de acceso a los pensamientos, aquello que Frege efectivamente dice sobre el pensar, o sea, el diferente modo en que trata el mismo problema que Lotze, no puede ser visto en su importancia. Los momentos del texto que obligarían a revisar $\mathrm{y}$, eventualmente, a matizar el propio principio interpretativo son simplemente pasados por alto. Importante es únicamente llegar a la playa segura de la "linguistic expression". Otros claros ejemplos de similar unilateralidad de perspectiva, se encuentran en Bell, 1979, pp. 108 y 112 y Barry Smith, 1989, pp. 4-5, 6-7 y 11.

${ }^{87}$ Como los ya citados Mohanty, Willard, Bell, Smith, Peucker y Bégout.

Manuscrito - Rev. Int. Fil., Campinas, v. 37, n.2, pp. 357-413, jul.-dez. 2014. 
Tc. que Frege identifica psicología y psicología naturalista ${ }^{88}$.

Como consecuencia de la anterior, se puede avanzar en el sentido de la tesis

Td. de que justamente porque Frege no posee ningún interés por la subjetividad asume, sin más, la concepción de subjetividad de la psicología naturalista de un modo totalmente acrítico, de forma tal que él posee en realidad una concepción de la subjetividad y, en verdad, una concepción naturalista y no-intencional ${ }^{89}$.

3. Sobre la base de lo dicho, podemos resumir nuestra posición correspondientemente en cuatro puntos. Ciertamente, no existe duda de que Frege afirma Ta y Tc. No obstante, existen buenas razones para creer que de ningún modo él afirma Tb y Td. Más aun, ni Tb se sigue de Ta ni Td de Tc, o sea, que no porque Frege remita el problema de la aprehensión de los pensamientos a la psicología se sigue que no tenga interés alguno en la cuestión de la subjetividad, ni porque acepte sin cuestionar la psicología naturalista se debe asumir que él defiende una concepción "naturalística" y no-intencional ${ }^{90}$ de la conciencia. Vamos a desarrollar estos dos últimos puntos.

\footnotetext{
88 Mohanty, 1982, p. 32-33.

${ }^{89}$ Mohanty, 1982, p. 35 y 1989, p. 4; Bell, 1979, p. 112; Bégout, 2002, p. 121 y 127-128.

90 Por motivos que habrán de ponerse en evidencia más tarde (6 (1)), a partir de ahora uso en diferentes sentidos las expresiones "naturalista" y "naturalístico". Me inspiro para ello en una distinción efectuada por Husserl en el marco de la contraposición entre "naturalistische" und "personalistische Einstellung" en "Ideen II" (Hua, IV, p. 173ss.), a saber, entre "natürliche" y "naturalistische Einstellung" (Hua, IV, p. 180ss.). Entiendo por "naturalista" toda concepción de subjetividad que no efectúa la reducción transcendental; entiendo por „naturalística“ toda concepción de subjetividad que aborda la

Manuscrito - Rev. Int. Fil., Campinas, v. 37, n.2, pp. 357-413, jul.-dez. 2014.
} 
4. Tb-Ta: No cabe duda de que Frege no responde al problema de cómo captamos pensamientos y lo remite a la psicología ${ }^{91}$. Mas, de este hecho no se sigue en modo alguno que Frege desconsidera toda cuestión subjetiva o no dispone de una adecuada concepción de la subjetividad. Una tal inferencia implica pasar por alto, que no meramente en el cómo captamos pensamientos, sino ya en el que captamos pensamientos ${ }^{92}$, están asumidas decisiones esenciales con respecto a la concepción de subjetividad.

El error indicado es patente en la lectura usual del texto de la "Lógica" de 1897, el locus clásico para probar que Frege remite el problema de la aprehensión de pensamientos a la psicología ${ }^{93}$. Mas, justamente en este texto, si se lo lee con atención, es evidente que Frege efectúa esa remisión únicamente una vez que ha dado soporte a la tesis de que captamos pensamientos y esto, mediante la respuesta a una objeción de un oponente, que parte de una idea de subjetividad que presupone el $\mathrm{PI}^{94}$.

En suma, no es contradictorio remitir el problema de cómo aprehendemos pensamientos a la psicología, por un lado y, por otro, defender una cierta concepción de la subjetividad sino que, muy por el contrario, lo primero presupone necesariamente lo segundo. La pregunta ¿cómo aprehendemos pensamientos? solo tiene sentido sobre

misma (y, en particular, su relación al objeto) en una perspectiva mecánicocausal.

91 Willard, 1977, p. 47 y 1994, p. 238ss.; Barry Smith, 1994, p. 164-165 y 1989, p. 6-7. Compárese además: Malzkorn, 2001, p. 36, 38, 49 y 50; Dummett, 1990, p. 278.

${ }^{92} \mathrm{~L}$ (1897), p. 64.

${ }^{93}$ L (1897), pp. 63-64.

${ }^{94}$ Ver González Porta: Freges Logic von 1897 und die Subjektfrage.

Manuscrito - Rev. Int. Fil., Campinas, v. 37, n.2, pp. 357-413, jul.-dez. 2014. 
la base de una determinada concepción de subjetividad, a saber, aquella que niega de plano el PI95.

5. Td-Tc: Del hecho de que Frege presuponga la validez irrestricta de una psicología asociacionista no se deriva que tenga que compactar con el asociacionismo en su idea de subjetividad. La descripción que hemos efectuado de la concepción fregueana de la subjetividad muestra a las claras que ella no es ni teórico-representacional (vorstellungstheoretisch), ni asociacionista, ni "naturalística"96. Es cierto que Frege tiende a conceder de modo irrestricto los derechos de una psicología asociacionista ${ }^{97}$ y nunca considera la posibilidad de otra psicología, sea esta comprehensiva, general o descriptivo-intencional. No obstante, es un error leer la concepción fregueana de la subjetividad a partir de su

\footnotetext{
${ }^{95} \mathrm{Si}$ recorremos toda la polémica en torno al psicologismo, es una constante observar que un punto que los psicologistas consideran como decisivo a su favor, es que ellos evitan un problema que toda forma de antipsicologismo se ve obligado a enfrentar, a saber, que si es cierto que mis únicos objetos son mis representaciones, entonces está asegurado que yo puedo captar tales objetos (pues sería absurdo establecer una dificultad de principio en captar mis propias representaciones). Ahora bien, siempre que se afirme que la conciencia capta algo transcendente a ella, o sea, más allá de sus representaciones, nos enfrentamos al problema de cómo esto sea posible (objeción de Exner a Bolzano y de Kerry a Frege). En el caso de pensamientos, dado que ellos son por definición entidades transcendentes a la conciencia, es entonces un problema (y un serio problema), el cómo los captamos. (Frege expresamente reconoce esta dificultad al calificar la aprehensión de pensamientos como "misterio".) Si, por el contrario, reducimos pensamientos a representaciones, entonces desaparece el problema. En suma, la pregunta, cómo aprehendemos pensamientos, solo tiene sentido, sobre la base de que el que aprehendemos pensamientos es realmente un problema, y este solo es un problema si, al negar el PI, negamos toda reducción de pensamientos a representaciones.

${ }^{96}$ Compárese nota 90.

${ }^{97}$ G, p. 30 (58-59). Compare Mohanty, 1982, p. 32-33.
}

Manuscrito - Rev. Int. Fil., Campinas, v. 37, n.2, pp. 357-413, jul.-dez. 2014. 
idea de la psicología ${ }^{98}$, justamente porque ambas no están en una relación armoniosa, sino que se encuentran en tensión. Más aún, hay en Frege una explícita crítica de la psicología de su época, que ha sido pasada por alto y que se encuentra en la nota al pie de página de la "Lógica" de 1897 a la cual ya nos hemos referido" 99.

6. Ciertamente hay algo de verdadero en la concepción standard de Frege y es el percibir los notorios límites del tratamiento fregueano de la cuestión de la subjetividad, los cuales resaltan con evidencia, sobre todo, cuando el mismo es comparado con Husserl. Límites, no son, sin embargo, la nada absoluta. Este es el punto decisivo. La formulación adecuada es: existe en Frege no meramente una crítica radical del psicologismo, que desconsidera toda perspectiva subjetiva, sino una concepción de subjetividad, la cual tiene contornos definidos y no puede ser subestimada. No obstante, para producir una imagen realmente equilibrada, no se debe apuntar únicamente a los claros

98 Compárese Mohanty, 1982, pp. 3-4 y 35. Algo similar a Mohanty se encuentra en Bégout, con el agravante de que este no permanece en un plano genérico, sino que aplica explícitamente tal punto de vista a la noción de pensamiento, contradiciendo así inequívocamente la literalidad del texto fregueano (Bégout, 2002, p. 127).

99 L (1897), p. 64 n. Para probar la conciencia fregueana del carácter problemático del "grasping", Mohanty (1982, p. 37) cita el texto principal de la "Logik" de 1897, comenzando con la objeción: "But still the 'grasping'..." y subrayando el "misterio". Por tal razón, corta el texto de la nota al pie de página, no percibiendo la importancia de lo que sigue. En la cita de Mohanty, el texto dice únicamente: "I should say that this question of grasping thoughts and recognizing them to be true is still far from being grasped in all its difficulty." (Mohanty, 1982, p. 37). Es curioso que los pasajes referidos son profusamente citados sin que, no obstante, se fije adecuadamente su verdadero contenido (Prauss, 1976, p. 37-38; Willard, 1994, p. 239; Bégout, 2002, p. 130). Peucker (2002, p. 152) es uno de los pocos que perciben que hay aquí al menos una oscilación en la posición fregueana, aun cuando no extrae de su observación ninguna consecuencia.

Manuscrito - Rev. Int. Fil., Campinas, v. 37, n.2, pp. 357-413, jul.-dez. 2014. 
textos en donde Frege delinea una concepción de subjetividad, sino también, y en estrecha correlación, a los límites de la posición fregueana. Estos se concentran en los siguientes puntos:

a. Frege no tiene la idea positiva de una psicología alternativa a la asociacionista.

b. Frege no meramente no establece el proyecto de una tal, lo cual posiblemente sea algo tanto innecesario cuanto desvinculado de su propuesta filosófica, sino que tampoco toma nota de que, de hecho, existen psicologías alternativas (Natorp, Dilthey, Brentano).

c. No es claro cuál es el "locus" sistemático desde el cual Frege efectúa sus afirmaciones respecto de la subjetividad, el cual, obviamente no puede ser aquel de la considerada por él psicología "positiva" pues, como vimos, la contradice y cuestiona ${ }^{100}$.

d. Por lo anterior, quizás como causa, y quizás como consecuencia, Frege no tiene una fundamentación metódica de sus afirmaciones.

e. Aceptando que Frege sea el inicio del semantic turn, debe decirse que este inicio es "pre-crítico" en cuanto todo el potencial de la virada lingüística con respecto a la cuestión de la subjetividad, que habrá de desenvolverse claramente en Wittgenstein, no está ni siquiera insinuado. Frege no efectúa una crítica del lenguaje que hable del sujeto (con la única excepción de sus

100 Dejo abierta la pregunta, que no obstante considero decisiva, de si lo que Frege efectivamente "hace" exige la idea de una teoría filosófica de la subjetividad, o es suficiente para ello una adecuada revisión de la psicología "científica".

Manuscrito - Rev. Int. Fil., Campinas, v. 37, n.2, pp. 357-413, jul.-dez. 2014. 
breves manifestaciones sobre los colores y el indexicalia "yo"), sino que habla de este sin más en el lenguaje-objeto ${ }^{101}$.

7. Sabemos que es usual subrayar que Frege no tiene una respuesta para la importante pregunta de cómo captamos pensamientos, remitiendo esta a la psicología. Lo cierto es que, no obstante lo anterior, justo en el texto usualmente citado, Frege oscila con respecto a cuál sea el problema que es remitido a la psicología, considerando el mismo a veces como el pensar, a veces como el juzgar, a veces no diferenciando entre ambos e, incluso, a veces como ambos ${ }^{102}$. Si sobre la base de la anterior observación, atendemos a otros textos fregueanos, veremos que es inequívoco que el problema que Frege remite a la psicología es en realidad doble, a saber, referente al pensar y al juzgar en sus sentidos precisos ${ }^{103}$. Si esto es así, entonces, aun cuando se pueda afirmar que Frege no explica el "cómo" aprehendemos pensamientos, no se puede ignorar que Frege sí ofrece importantes elementos a los efectos de una respuesta a la pregunta cómo juzgamos (aun cuando, por otro lado, también remita esta pregunta a la psicología), a saber, que lo hacemos

${ }^{101}$ La concepción fregueana de la relación del sujeto con el lenguaje merecería un estudio especial.

102 Véase con respecto a oscilaciones en el texto de 1897, por un lado, la referencia exclusiva al pensar (p. 64) o al juzgar (p. 65), por otro, el aparente nivelamiento de pensar y juzgar (p. 64-65) y, por otro, finalmente, la clara diferenciación de ambos problemas (p. 65).

103 ALD, p. 273. Además de lo observado en el texto principal, un punto merece atención en este pasaje, a saber, que Frege retoma en el mismo dos cuestiones tratadas en la "Lógica" de 1897: por un lado, el referir a la psicología tanto la cuestión del pensar como la del juzgar; por otro, el insistir en que en ambos casos hay algo no-psíquico en juego, el pensamiento. Esto pone a las claras la firmeza de las convicciones fregueanas, que no pueden ser rebajadas a observaciones circunstanciales pues se mantienen inmodificadas a través de los años en algo que, como lo es todo lo referente a la subjetividad, está fuera de su interés central.

Manuscrito - Rev. Int. Fil., Campinas, v. 37, n.2, pp. 357-413, jul.-dez. 2014. 
en cuanto el juzgar implica una toma de decisión (o elección), siendo que las decisiones no están sometidas a las leyes asociativas ${ }^{104}$.

8. Dos últimos puntos con respecto a la lectura standard de Frege:

a. En la base de la lectura standard de Frege se encuentra una cierta comprensión, errónea, de en qué consiste el antipsicologismo fregueano. La gran mayoría de los autores se aproximan a Frege a partir de un esquema preconcebido que tiene su fuente de inspiración última en el prefacio a los "Prolegómenos" husserlianos. Según este esquema, la oposición de Frege al psicologismo consiste en una afirmación dogmática de la existencia de objetos ideales ${ }^{105}$. Este esquema es falso y pasa por alto que ya en Frege la crítica al psicologismo es una crítica a la idea psicologista de subjetividad y que, por tanto, ella no se mueve meramente en el marco de una contraposición ontológica (objetos ideales - reducción psicológica), sino también epistemológica (mis únicos objetos son representaciones - puedo captar objetos que no son representaciones). La crítica de Frege al psicologismo no reside únicamente en ver el psicologismo como un error respecto de aquello que "hay", sino también de aquello que puede ser objeto de conocimiento. Si leemos la crítica fregueana al psicologismo en el modo ontológico, y pasamos por alto el esencial aspecto epistemológiconoético de la misma, entonces la consecuencia necesaria es subrayar una omisión esencial de Frege respecto de la cuestión de la aprehensión de los pensamientos.

104 Peucker pasa esto por alto al observar que Frege no meramente no explica cómo se opera la captación de pensamientos, sino tampoco "wie dieser anerkennende Charakter des Urteilens seinerseits genau zu verstehen ist." (Peucker, 2002, p. 152).

105 Compárese por ejemplo Peucker, 2002, p. 149-150.

Manuscrito - Rev. Int. Fil., Campinas, v. 37, n.2, pp. 357-413, jul.-dez. 2014. 
b. Es usual en la visión standard afirmar que Frege reduce la teoría del conocimiento a la psicología ${ }^{106}$ y es sabido que existe una importante línea interpretativa que ha insistido en que la filosofía fregueana es esencialmente una teoría del conocimiento ${ }^{107}$. Por tal razón, importa observar que nuestra afirmación en el sentido de que Frege posee una concepción de subjetividad no debe ser identificada sin más con la tesis de que Frege posee una teoría del conocimiento o que la teoría del conocimiento es un objetivo primario de su reflexión. Sin prejuicio de lo anterior, ella posibilita ubicar esta tesis de un modo más diferenciado en cuanto sugiere una serie de distinciones que son relevantes en dicho contexto, a saber, entre una teoría del conocimiento en sentido objetivo y una en sentido subjetivo (Erkenntniskritik - Erkenntnistheorie) ${ }^{108}$, entre teoría del conocimiento strictu sensu y noética ${ }^{109}$, entre la distinción psicología-lógica, por un lado, y psicología-teoría del conocimiento ${ }^{110}$, por otro, así como entre el hecho de que Frege no establece una

106 Prauss, 1976, pp. 34 y 38; Peucker, 2002, p. 152. Obsérvese que tanto Prauss como Peucker identifican el problema de la teoría del conocimiento con el problema de la aprehensión de pensamientos.

107 Kitcher, 1979 y Lotter, 2004. Lotter (2004, p. 14) incluye dentro de esta tendencia, además de la ya citada Kitcher, a Hans Sluga, Tyler Burge, Gregory Currie, Gottfried Gabriel, Thomas Ricketts y Joan Weiner.

${ }^{108}$ Esta distinción aparece por primera vez en Hermann Cohen (PI, 45-53). "Erkenntnistheorie" designa el problema del conocimiento tal como él fue concebido por la filosofía moderna, o sea, como una cuestión que supone como uno de sus elementos un sujeto entendido en sentido psicológico. En contraposición, "Erkenntniskritik" designa la idea de un análisis del contenido objetivo de enunciados tendiente a su fundamentación puramente lógica, sin referencia alguna a un sujeto. La "Erkennntniskritik" neokantiana es un antecedente de lo que hoy llamaríamos "epistemología" o "filosofía de la ciencia".

${ }^{109} \mathrm{O}$ sea, entre legitimación de atribución de valores de verdad, por un lado, y legitimación de la posibilidad de acceso a algo "objetivo" tal como, por ejemplo, un pensamiento en sentido fregueano. Veáse nota 106. 110 RC, p. 102.

Manuscrito - Rev. Int. Fil., Campinas, v. 37, n.2, pp. 357-413, jul.-dez. 2014. 
relación entre ambas distinciones y, no obstante, en pasajes explícitos separa teoría del conocimiento y psicología ${ }^{111}$.

\section{A modo de conclusión: crítica al psicologismo y concepción intencional da subjetividad}

1. Se ha pretendido señalar deficiencias de dos órdenes en el antipsicologismo fregueano, a saber, o bien que Frege no fundamenta suficientemente su antipsicologismo, o bien que Frege no supera definitivamente el psicologismo. Como vimos, es parte de la opinión standard considerar que Frege mantiene el concepto de subjetividad del psicologismo que combate. No obstante, se argumenta a menudo, una superación plena del psicologismo solo puede efectuarse mediante una superación de la concepción psicologista de la subjetividad, más concretamente, ella implica el abandono de todo naturalismo y, más aún, en definitiva, una reducción transcendental en el sentido husserliano. Es esta la opinión de Mohanty (1982, pp. 99 y 115-116). Siguiendo lo que ya es consenso entre aquellos que se han ocupado del tema desde Natorp en adelante, no puedo más que concordar con que una superación del psicologismo necesariamente supone una superación del concepto psicologista de subjetividad. Ahora, por "superación del concepto psicologista de la subjetividad" Mohanty entiende dos cosas diferentes y diferenciables, a saber, o una concepción intencional de la conciencia, o una concepción transcendental de la misma. Concuerdo con la primera tesis, discrepo con la segunda. El psicologismo solo es superable mediante una concepción trascendental de la conciencia una vez que, primeramente, se supone la verdad de la tesis idealista. Pero, ¿acaso no es pensable una superación del psicologismo en el marco de un realismo? Dejando de lado Frege, ¿debemos pensar que la airada resistencia de un Brentano al

${ }^{111}$ L (1879-1891), p. 3.

Manuscrito - Rev. Int. Fil., Campinas, v. 37, n.2, pp. 357-413, jul.-dez. 2014. 
platonismo de sus detractores era absolutamente infundada? Si para superar el psicologismo es necesaria una concepción trascendental de la conciencia, entonces con certeza Frege no ha superado el psicologismo. Sin embargo, si para superar el psicologismo es necesaria una concepción intencional de la subjetividad o, en términos más generales, una concepción no-"naturalística" de la subjetividad, entonces no puede caber dudas que Frege superó el psicologismo ${ }^{112}$.

2. Ciertamente, se puede afirmar la existencia de una concepción de la subjetividad en Frege sin, no obstante, calificar la misma como "intencional". Esto es, la calificación de la concepción fregueana como intencional no es esencial a nuestra tesis y se puede conceder la segunda sin la primera. Existen buenas razones para no usar el término "intencional" en relación a Frege ${ }^{113}$, como, por ejemplo, la dificultad fregueana para admitir actos sin objetos ${ }^{114}$. Si, no obstante, lo hemos hecho, ha sido en base a las siguientes consideraciones:

112 Dicho de otra forma: si entendemos por "naturalista" toda concepción de subjetividad que no efectúe la reducción transcendental, entonces ciertamente Frege es "naturalista", pues no efectúa tal reducción. Si lo anterior es cierto, y como el naturalismo conduce necesariamente al psicologismo, entonces Frege también es psicologista. Esta consecuencia me parece a todas luces absurda y, por tanto, debemos rever en su base los presupuestos que conducen a la misma. Esta revisión obliga a distinguir, tal como lo hemos hecho en la nota 90, entre una concepción de subjetividad "naturalista" y una "naturalística". Mohanty no ha sido el único que, desde una perspectiva idealistatrascendental, considera que la superación fregueana del psicologismo es inconsecuente (Véase Prauss, 1976, p. 37-38; Bégout, 2002, p. 127; Peucker, 2002, p. 153). Según Peucker, la falta de una concepción trascendental de subjetividad en Frege va ligada a la falta de una teoría del conocimiento o a la asimilación de la misma a la psicología.

113 Mohanty,1982, pp. 36-37 y 112; Willard, 1994, p. 248.

114 Barry Smith, 1978, p. 119; Mohanty, 1982, p. 110; Willard, 1994, p. 248. Mohanty funda básicamente su análisis en un texto de „Der Gedanke“ (G, p.

Manuscrito - Rev. Int. Fil., Campinas, v. 37, n.2, pp. 357-413, jul.-dez. 2014. 
a. Si se establece como condición de hablar de intencionalidad el admitir la posibilidad de actos sin objetos, entonces Twardowsky y Meinong no tienen concepciones intencionales y alguno podría incluso sentirse en el derecho de decir algo similar con respecto a Brentano ${ }^{115}$.

b. Si se dice por ejemplo, de un lado, que no basta con la mera dirección al objeto sino que debe suponerse además algún tipo de estructura interna del acto que posibilite dicha dirección y, más concretamente, el porqué de la dirección a un determinado objeto, por el otro, entonces, no solo no existe intencionalidad en Meinong, sino tampoco en el mismísimo Brentano ${ }^{116}$.

c. Si se pretende que solo se puede hablar de intencionalidad en sentido propio en el contexto de una teoría de la equivocidad del ser y, en consecuencia, de la distinción entre ser-real y ser-objetivo, insistiéndose en el cuño aristotélico, realista y anti-platónico de este concepto ${ }^{117}$, entonces no solo Frege, con su postulación platonizante de objetos ideales, sino tanto el Husserl idealista en el sentido de "Investigaciones lógicas" como el Husserl idealista, en el sentido de la reducción trascendental (para quien, en última instancia, hay univocidad del ser en

42 (68). El objetivo de este texto, sin embargo, no es abordar el problema de las representaciones sin objeto, sino subrayar que nunca dos sujetos pueden aprehender la misma representación (Cfe. Schulte, 1984, p. 73). Que no se debe pensar que necesariamente Frege considera que las representaciones ocupan el lugar del objeto en las representaciones sin objeto (gegenstandslose Vorstellungen), surge con claridad de un texto como L (1897), pp. 40-41, el cual, asimismo, muestra el verdadero contexto sistemático del pasaje anteriormente citado.

115 Barry Smith, 1989, p. 11-12.

116 Mohanty, 1982, p. 65. Lo que Mohnaty dice respecto de Moore se aplica mutatis mutandis a Brentano. Que Mohanty no se encuentra aquí en una posición muy cómoda surge de su propio texto (Mohanty, 1982, p. 36).

117 Debo esta objeción a Pedro Monticelli.

Manuscrito - Rev. Int. Fil., Campinas, v. 37, n.2, pp. 357-413, jul.-dez. 2014. 
tanto ser es siempre ser para una conciencia), no poseen una noción de intencionalidad.

d. En suma, todos los argumentos empleados para negar la existencia de intencionalidad en Frege terminan conduciendo, si son desarrollados plenamente, a consecuencias contraintuitivas. La razón de ello es que, de diferentes formas, en tales argumentos se identifica el concepto de intencionalidad en cuanto tal con una concepción específica de intencionalidad (sea la husserliana, sea la brentaniana), con lo cual se restringe de modo ilegítimo (o, al menos, innecesario) este concepto. En tal sentido parece preferible mantener un concepto de intencionalidad amplio que, aun cuando no responda exactamente a ningún concepto histórico efectivo, permite hablar de diferentes concepciones de intencionalidad en el marco de un núcleo común. Una restricción severa del uso del término "intencionalidad" es tan infundada como lo sería la restricción de cualquier término del vocabulario filosófico a una forma histórica específica, por ejemplo, identificando realismo con realismo aristotélico, idealismo trascendental con Kant o positivismo con Comte.

3. Sin perjuicio de las precisiones anteriores, el hecho relevante que debe ser aceptado, aun cuando se tengan reservas de hablar de una idea intencional de la conciencia en Frege, es que su concepción de subjetividad es a todas luces no-naturalística y, más aún, que ella rompe radicalmente con la concepción moderna mayoritaria. Es esto lo que, en última instancia, no puede ser y, hasta ahora, no obstante, ha sido pasado por alto.

Manuscrito - Rev. Int. Fil., Campinas, v. 37, n.2, pp. 357-413, jul.-dez. 2014. 


\section{REFERÊNCIAS BIBLIOGRÁFICAS}

BAKER, G. P. y HACKER, P. M.S.: Frege: Logical Excavations. Oxford, Oxford University Press, 1984. . "Frege's Antipsychologism". In: NOT'TURNO, M. (org.): Perspectives on Psychologism. Leiden / New York / Köbenhavn / Köln, E. J. Brill, (1989), pp. 75-127.

BÉGOUT, B. La pensée en acte: logique et activité de penser chez Frege et Husserl. In: BRISART, R. (ed.): Husserl et Frege. Les ambiguités de l'antipsychologisme. Paris, Vrin, (2002), pp. 117-153.

BELL, D. Frege's Theory of Judgment. Oxford, Clarendon Press, 1979.

Reference, Experience and Intentionality. In: HAAPARANTA, Leila: Mind, Meaning and Mathematics. Essays on the philosophical Views of Husserl and Frege. Dordrecht / Boston / London, Kluwer Academic Publishers, 1994.

BIRO, J. and KOTAKO, P. Frege: sense and reference one bundred years later. Dordrecht, Kluwer, 1995.

BLUMENBERG, H.: Transzendenz und Immanenz. In: von CAMPENHAUSEN, Hans; DINKLER, Erich; GLOEGER, Gerhard; GALLING, Kurt (eds.): Die Religion in Geschichte und Gegenwart. Handwörterbuch für Theologie und Religionswissenschaft. 3. Aufl. Tübingen, Mohr Siebeck, (1959), Bd. 6, pp. 989-997.

BOEHM, R. Vom Gesichtspunkt der Phänomenologie. Husserl-Studien. Den Haag, Martinus Nijhoff, 1968.

BRELAGE, . Transzendentalphilosophie und konkrete Subjektivität. In: BRELAGE, Manfred: Studien zur Transzendentalphilosophie. Berlin, Walter de Gruyter, 1965.

Manuscrito - Rev. Int. Fil., Campinas, v. 37, n.2, pp. 357-413, jul.-dez. 2014. 
BRENTANO, F.: Psychologie vom empirischen Standpunkt. 2 vols. Hamburg, Meiner, 1973. . Deskriptive Psychologie (DP). Hamburg, Meiner, 1982.

BRISART, R. Husserl et Frege. Les ambiguités de l'antipsychologisme. Paris, Vrin, 2002.

CARL, W. Frege's Theory of sense and reference. Its origins and Scope. Cambridge, Cambridge University Press, 1994.

CAMPENHAUSEN, H.; DINKLER, E.; GLOEGER, G. \& GALLING, K. Die Religion in Geschichte und Gegenwart. Handwörterbuch für Theologie und Religionswissenschaft. 3. Aufl. Tübingen, Mohr Siebeck, Bd. 6, 1959.

COHEN, H. Logik der reinen Erkenntnis (LRE). Berlin, Bruno Cassirer, 1902 (2.verb. Aufl. 1914). - Das Prinzip der Infinitesimal-Methode und seine Geschichte. Ein Kapitel zur Grundlegung der Erkenntniskritik (PI). Frankfurt /M, Suhrkamp, 1968.

- Kants Begründung der Ethik (KBE). Berlin, Ferd. Dünnler Verlagsbuchhandlung, 1876.

CURRIE, G. Frege on thoughts. Mind, v. 89, pp. 234-248, 1980. . Frege: an introduction to his philosophy. New Jersey, The Harvester Press - Barnes Nobles Books, 1982. - Remarks on Frege's Conception of Inference. Notre Dame Journal of formal Logic. v. 28. Number 1. January, pp. 55-68, 1987.

DE BOER, T. The Development of Husserl's Thought. The Hague / Boston / London, Martinus Nijhoff, 1978.

ERDMANN, B. Logik. Logische Elementarlehre (L). Halle, Niemeyer, 1892. 
DRUMMOND, J. J. Frege and Husserl: Another look at the issue of influence. Husserl Studies, n 2, pp. 245-265, 1985.

DUMMETT, M.: Frege and other philosophers. Oxford, Clarendon Press, 1990.

FISCHER, K.: System der Logik und Metaphysik oder Wissenschaftslehre (SLM). Heidelberg, Manutiuis Verlag, 1865.

FISSETE, D. Logique et philosophie chez Frege et Husserl. In: BRISART, R. (ed.): Husserl et Frege. Les ambiguités de l'antipsycyhologisme. Paris, Vrin, (2002), pp. 49-74.

FÖLLESDALL, D. Husserl und Frege. Ein Beitrag zur Beleuchtung der Entstehung der phänomenologischen Philosophie. Oslo, Ascheloug, 1958.

FREGE, G.: Begriffsschrift. Eine der arithmetischen nachgebildeten Formelsprache des reinen Denkens. In: Begriffsschrift und andere Aufsätze. 2a. ed. Ignacio Angelelli (ed.). Darmstadt, Wissenschaftliche Buchgesellschaft, pp. 1-88, 1971 (Beg).

Die Grundlagen der Arithmetik. Eine logisch mathematische Untersuchung über den Begriff der Zab (GA)l. Hamburg, Meiner, 1988.

. Grundgesetze der Arithmetik (GGA). Jena, Pohl, 1893.

. Logik (1897). In: GABRIEL, Gottfried (org.): Scbriften zur Logik und Sprachphilosophie. Aus dem Nachlass. Hamburg, Meiner, (1980), 3. Aufl. (L (1897)).

- Der Gedanke (G). In: FREGE, Gottlob: Logische Untersuchungen. Göttingen, Vandenhoeck und Ruprecht, 1986.

_. Logische Untersuchungen. Göttingen, Vandenhoeck und Ruprecht, 1986.

Manuscrito - Rev. Int. Fil., Campinas, v. 37, n.2, pp. 357-413, jul.-dez. 2014. 
. Besprechung Husserl's Philosophie der Arithmetik, Zeitschrift für Philosophie und philosophische Kritik (BH), NF. 103, pp. 313-332, 1894.

. Logik (1879-1891). In: FREGE, Gottlob: Nachgelassene Schriften. Hermes, Hans; Kambartel, Friedrich y Kaulbach, Friedrich (eds.). Hamburg, Felix Meiner, (1969), pp. 1-8 (L (1879-1891)).

. Über das Trägheitsgesetz. In: Kleine Schriften. Angelelli, I. (ed.). Hildesheim / Zürich / New York, Olms, (1990), pp. 113-124 (ÜT).

- Logische Allgemeinheit. In: GABRIEL, Gottfried (org.): Schriften zur Logik und Sprachphilosophie. Aus dem Nachlass, Hamburg, Meiner, (1980), 3. Aufl., pp. 166-171 (LA).

. Über Sinn und Bedeutung (SB). In: FREGE, Gottlob: Funktion, Begriff, Bedeutung. PATZIG, Günther (ed.). Göttingen, Vandenhoeck \& Ruprecht, (1986), pp. 40-65.

. Erkenntnisquellen der Mathematik und der mathematischen Naturwissenschaften (EQ). In: FREGE, Gottlob: Nachgelassene Schriften. Hermes, H.; Kambartel, F. y Kaulbach, F. (eds.). Hamburg, Meiner, (1969), pp. 286-294.

. Logik in der Mathematik (LM). In: GABRIEL, Gottfried (org.): Schriften zur Logik und Sprachphilosophie. Aus dem Nachlass. Hamburg, Meiner, 3. Aufl., (1980) pp. 92-155.

. Aufzeichnungen für Ludwig Darmstädter (ALD). In: FREGE, Gottlob: Nachgelassen Schriften. Hermes, H.; Kambartel, F. y Kaulbach, F. (eds). Hamburg, Meiner, (1969), pp. 273-278

. Einleitung in die Logik (EL). Nachgelassene Schriften. Hermes, Hans; Kambartel, Friedrich y Kaulbach, Friedrich (eds.). Hamburg, Meiner, pp. 201-213, 1969. 
- Rezension von Hermann Cohen (RC): Das Prinzip der Infinitesimal- Methode und seine Geschichte (1895). In: FREGE, Gottlob: Kleine Schriften. Angelelli, Ignacio (ed). Hildesheim / Zürich / New York, Olms, (1990), 2te. Aufl., pp. 99-102.

. Die Verneinung. In: FREGE, Gottlob: Logische Untersuchungen. Patzig, Günther (ed). Göttingen, Vandenhoeck und Ruprecht, 1986, pp. 54-71 (V)

. Gedankengefüge. In: FREGE, Gottlob: Logische Untersuchungen. Patzig, Günther (ed.). Göttingen, Vandenhoeck und Ruprecht, (1986), pp. 72-91 (GG)

GABRIEL, G.: Freges "verborgene" Erkenntnistheorie. In: GERHARD, V., HEROLD, N.: Perspektiven des Perspektivismus. Gedankenschrift zum Tode Friedrich Kaulbach. Würzburg, Königshausen \& Neumann, (1992), pp. 67-86.

; DATHE, Uwe Gottlob Frege Werk und Wirkung. Paderborn, Mentis, pp. 123-136, 2000.

. (org.): Schriften zur Logik und Sprachphilosophie. Aus dem Nachlass. Hamburg, Meiner, 1980.

GERHARD, V., HEROLD, N.: Perspektiven des Perspektivismus. Gedankenschrift zum Tode Friedrich Kaulbach. Würzburg, Königshausen \& Neumann, 1992.

GONZÁLEZ PORTA, M. A.: Transz̨endentaler „Objektivismus”. Bruno Bauchs kritischer Verarbeitung des Themas der Subjektivität und ibre Stellung innerhalb der Neukantianischen Bewegung. Frankfurt am Main / Bern / New York / Paris, Peter Lang, 1989. 
- Los orígenes de la virada antipsicologista en Husserl (La reseña a Schröder de 1891 revisada). Thémata. Revista de Filosofía, Sevilla, v. 21, pp. 85-116, 1999.

. La cuestión noética en Frege, su concepto de intencionalidad y su influencia sobre Husserl. Thémata. Revista de Filosofía, Sevilla, v. 24, pp. 83-114, 2000.

- Platonismo e intencionalidade: a propósito de Bernhard Bolzano. Sintese, Belo Horizonte. Primeira parte, v. 29, n 94 , pp. 251-275, 2002. Segunda parte, v. 30, n. 96, pp. 85-106, 2003.

A polémica em torno ao psicologismo de Bolzano a Heidegger. Sintese, Belo Horizonte, v. 31, n 99, pp. 107-133, 2004

- Frege y Natorp: platonismos, psicologismos y teorías de la subjetividad. O que nos faz pensar, Rio de Janeiro, v. 20, pp. 163184, 2006.

. Es el psicologismo refutable según Frege? Revista de Filosofia Aurora, Curitiba, v. 21, pp. 545-568, 2009.

. A crítica de Frege ao idealismo em "Der Gedanke". Veritas, Porto Alegre, v. 54, pp. 130-154, 2009.

- Psicologismo transcendental e psicologia fenomenológica. Natureza Humana, São Paulo, v. 12, pp. 197-228, 2010.

. Psicologismo e idealismo em Frege e Husserl. Sintese, Belo Horizonte, v. 37, pp. 57-66, 2010.

- Algunas consideraciones en torno a la distinción de tipos de psicologismo en Husserl. Cognitio. Revista de Filosofia, São Paulo, v. 11, n 2, pp. 279-302, 2010.

Manuscrito - Rev. Int. Fil., Campinas, v. 37, n.2, pp. 357-413, jul.-dez. 2014. 
.Frege e Natorp. Platonismos, Anti-psicologismos e teorías da subjetividade. In: GONZÁLEZ PORTA, Mario Ariel: Estudos Neokantianos. São Paulo, Loyola, 2011.

. Estudos Neokantianos. São Paulo, Loyola, 2011.

. La evolución de la crítica fregueana al psicologismo. Veritas, Porto Alegre, v. 57, n² 2, pp. 99-122, 2012.

- Currie y la interpretación literal de la tesis fregueana de la causalidad de pensamientos. Cognitio. Revista de Filosofia, São Paulo, v. 13, n 2, pp. 301-318, 2012.

. E. Husserl: Psicologismo, Psicologia, Fenomenologia. São Paulo, Loyola, 2013.

- Frege sobre "decisiones" (Entschlüsse). Intencionalidad y motivación en Frege y Husserl. Revista de filosofía. Aurora, Curitiba, v. 25, no 37,pp. 289-303, 2013.

- Cuál es propiamente la pregunta que Frege remite a la psicología? Philósophos, Goiana, v. 18, n 2, pp. 205-234, 2013.

. Freges "Logik" von 1897 und die Subjektfrage. (De próxima aparición)

- "Horror subjectivi". La polémica entre Frege y Kerry en torno al método psicológico. Sintese. Revista de Filosofia, Belo Horizonte, v. 41, n. 129, pp. 35-54, 2014.

HAAPARANTA, Leila: Mind, Meaning and Mathematics. Essays on the philosophical Views of Husserl and Frege. Dordrecht / Boston / London, Kluwer Academic Publishers, 1994.

HERMES, H.; KAMBARTEL, F. y KAULBACH, F. Hamburg, Meiner, pp. 286-294, 1969.

Manuscrito - Rev. Int. Fil., Campinas, v. 37, n.2, pp. 357-413, jul.-dez. 2014. 
HUSSERL, E. Logische Untersuchungen. Erster Band. Prolegomena zur reinen Logik. Ed. Elmar Holenstein. The Hague, Martinus Nijhoff, 1975. (Husserliana, XVIII).

Logische Untersuchungen. Zweiter Band. Erster Teil. Untersuchungen zur Phänomenologie und Theorie der Erkenntnis. Ed. Ursula Panzer, The Hague, Martinus Nijhoff, 1984. (Husserliana, XIX/1).

Logische Untersuchung. Zweiter Band. Zweiter Teil: Untersuchungen zur Phänomenologie und Theorie der Erkenntnis. Ed. Ursula Panzer, The Hague, Martinus Nijhoff, 1984. (Husserliana XIX/2)

. Philosopbie der Arithmetik. Mit ergänzenden Texten (1890-1901).

Ed. Lothar Eley. The Hague, Martinus Nijhoff, 1970. (Husserliana, XII).

- Briefwechsel. Band V. Die Neukantianer. Husserliana Dokumente. Dordrecht / Boston / London, Kluwer, 1994.

- Ideen zu einer reinen Phänomenologie und phänomenologischen Philosophie. Zweites Buch: Phänomenologische Untersuchungen zur Konstituition. Ed. Marly Biemel. The Hague, Martinus Nijhoff, 1952. (Husserliana IV)

- Aufsätze und Vorträge. 1911-1821. Mit ergänzenden Texten. Ed.

Thomas Nenon und Hans Reiner Sepp. The Hague, Martinus Nijhoff, 1986. (Husserliana XXV)

KEMMERELING, A. Über den Sinn des Wortes Ich. Grazer Philosophische Studien, 51, pp. 1-22, 1997.

KERRY, B.: "Über Anschauung und ihre psychische Verarbeitung. Vierter Artikel" (ÜApsV), Vierteljahresschrift für wissenschaftliche Philosophie, 11, pp. 249-307, 1887. 
KITCHER, P. Frege's Epistemology. Philosophical Review, 88, pp. 235282, 1979.

- Kant's Transcendental Psychology. Oxford, Oxford University Press, 1990.

KÜNNE, W.: Die philosophische Logik Gottlob Freges. Frankfurt, Klostermann, 2010.

KUNG, G.: Review of Mohanty's „Husserl and Frege: a new Look at their Relationship". Philosophy and phänomenological Research. v. 46, $\mathrm{n}^{\circ} 2$, pp. 344-348, 1985.

KUTSCHERA, F. V. Gottlob Frege. Eine Einführung in sein Werk. Berlin / New York, Walter de Gruyter, 1989.

KUSCH, M. Psychologism. A Case Study in the Sociology of Philosophical Knowledge. London / New York, Routledge, 1995.

LIPPS, T. Grundzüge der Logik (L). Hamburg / Leipzig, Verlag von Leopold Voss, 1893.

LOCKE, J. An essay concerning human understanding. Complete and unabridged. Collated and annotated by Alexander Campbell Fraser. New York, Dover.

LOTTER, D. Logik und Vernunft. Freges Rationalismus im Kontext seiner Zeit. Freiburg / München. Alber, 2004.

LOTZE, H. Logik. Drei Bücher vom Denken, vom Untersuchen und vom Erkennen (L). Misch, Georg (ed.). Leipzig, Meiner, 1912. . Die Philosophie in den letzten 40 Jahren (1880). In: LOTZE, Hermann: Logik. Drei Bücher vom Denken, vom Untersuchen und vom Erkennen. Misch, Georg (ed.). Leipzig, Meiner, pp. XCIV-CXXII, 1912.

Manuscrito - Rev. Int. Fil., Campinas, v. 37, n.2, pp. 357-413, jul.-dez. 2014. 
MCINTYRE, R. Husserl and Frege. The Journal of Philosophy, LXXXIV, pp. 528-535, 1987.

MALZKORN, W. How do we Grasp a thought Mr. Frege? In: NEWEN, A.; NORTMANN, U. y STUHLMAN-LAEISZ, R.: Building on Frege. New Essays on Sense, Content and Concept. Stanford, CSLI Publications, (2001), 35-52.

MOHANTY, J. N.: Husserl und Frege. Bloomington, Indiana University Press, 1982.

- Psychologism. In: NOTTURNO, M. A. (ed.): Perspectives on Psychologism. Leiden / New York / Kobenhavn / Köln, E. J. Brill, (1989), pp. 1-10.

. The concept of 'Psychologism' in Frege and Husserl. In: JACQUETTE, Dale (ed.): Philosophy, Psychology and Psychologism. Critical and Historical Readings on the Psychological Turn in Philosophy. Dordrecht / Boston / London, Kluwer Academic Publishers, pp.113-130, 2003.

. Husserl and Frege: a new Look at their Relationship. In: MOHANTY, J. H.: Readings on Edmund Husserl's Logische Investigations. The Hague, Martinus Nijhoff, (1977), pp. 22-32. . Readings on Edmund Husserl's Logische Investigations. The Hague, Martinus Nijhoff, 1977.

NATORP, P. Einleitung in die Psychologie nach kritischer Methode (EPs). Freiburg, 1888. . Über objektive und subjektive Methode (ÜOSM). Philosophische Monatshefte, XXIII, pp. 257-286, 1887.

. Bericht über deutsche Schriften zur Erkenntnistheorie aus den Jahren 1894 und 1895 (BDSE). Archiv für systematische Philosophie. 
STÜCK E. 3, pp. 101-121, 1897; STÜCK Z. 3, pp. 193-209, 1897; STÜCK D. 3, pp. 391-402, 1897.

. Zur Frage der logischen Methode (FLM). M. Bez. auf E. Husserls „Prolegomena zur reinen Logik”. Kant Studien, 6, pp. 270-283, 1901.

- Allgemeine Psychologie nach kritischer Methode (AP). Tübingen, Mohr, 1912.

NEWEN, A.; NORTMANN, U. y STUHLMAN-LAEISZ, R.: Building on Frege. New Essays on Sense, Content and Concept. Stanford, CSLI Publications, 2001.

NOTTTURnO, M. A. Perspectives on Psychologism. Leiden / New York / Kobenhavn / Köln, E. J. Brill, 1989.

ORTIZ, C. Word and Object in Husserl, Frege and Russell. The Roots of Twentieth-Century Philosophy. Athens, Ohio University Press, 1991.

PATZIG, G. Funktion, Begriff, Bedeutung. Göttingen, Vandenhoeck \& Ruprecht, 1986.

PECKHAUS, V.0 Benno Kerry. Beiträge zu seiner Biographie. History and Philosophy of Logik, 15, pp. 1-8, 1994.

PEUCKER, H. Von der Psychologie zur Phänomenologie. Husserls Weg in die Phänomenologie der „Logischen Untersuchungen“. Hamburg, Meiner, 2002.

PHILIPSE, H. Transcendental Idealism. In: SMITH, B. y WOODRUFF SMITH, D. (eds.): The Cambridge Companion to Husserl. Cambridge, Cambridge University Press, (1995), pp. 239322.

PICARDI, E. Kerry und Frege über Begriff und Gegenstand, History and Philosophy of Logik, 15, pp. 9-32, 1994. 
PRAUSS, G. Freges Beitrag zur Erkenntnistheorie. Überlegungen zu seinem Aufsatz „Der Gedanke“. Allgemeine Zeitschrift für Philosophie, 1/1, pp. 34-61, 1976.

RATH, M.: Der Psychologismusstreit in der deutschen Philosophie. Freiburg / München, Alber, 1994.

REID, T. Essays on the intellectual powers of man (EIPM). Cambridge, Mass., MIT Press, 1969.

REINHOLD, K. L. Versuch einer neuen Theorie des menschlichen Vorstellungsvermögens (VNTVM). 2a. ed. Prag / Jena, Widtmann und I. M. Mauke, 1796.

RICKERT, H. Der Gegenstand der Erkenntnis (GE). Ein Beitrag zum Problem derphilosophischen Transzendenz. Freiburg, Mohr, 1892.

RITTER, J. y GRÜNDER, K. Historisches Wörterbuch der Philosophie. Basel / Stuttgart, Schwabe \& Co. Verlag, 1976. Band IV: I-K.

RIVENC, F.; HUSSERL, W. y FREGE A. The Harvard Review of Philosophy, Spring, pp. 95-116, 1996.

ROSADO HADDOCK, G. E. A Critical introduction to the philosophy of Gottlob Frege. Hampshire, Aschgate, 2006.

SACHS-HOMBACH, K. Philosophische Psychologie im 19. Jabrbundert. Entstebung und Problemgeschichte. Freiburg / München, Alber, 1993.

SCHELER, M. Die transzendentale und die psychologische Methode (TPsM). Leipzig, Dürr, 1900.

SCHILDKNECHT, C. Die Reinigung im psychologische Waschkessel". Frege Psychologismus-Kritik und einige ihrer Konsequenzen. In: GABRIEL, G.; DATHE, U (eds.): Gottlob Frege Werk und Wirkung. Paderborn, Mentis, (2000), pp. 123-136. 
SCHOPENHAUER, A. Die Welt als Wille und Vorstellung. (1819, 1844 4a. ed.) Sämtliche Werke, Hg. Arthur Hübscher, v. 7, 2. Auf.. Wiesbaden, F. A. Brockhaus, 1949.

SCHULTE, J.: Frege... und kein Ende. Philosophische Rundschau, 31, pp. 60-79, 1984.

SCHUPPE, W. Grundriss der Erkenntnistheorie und Logik (EL). Berlin, Weldmannsche Buchhandlung, 1910.

SCHRIFTEN K. Y ANGELELLI, I. Hildesheim . Zürich (ÜT). New York, Olms, pp. 113-124, 1990.

SIGWART, C. Logik (L). 2 Bde. Tübingen, Mohr, 1904, 3te. Aufl.

SMITH, B. Husserl's Theory of Meaning and Reference. In: HAAPARANTA, Leila: Mind, Meaning and Mathematics. Essays on the philosophical Views of Husserl and Frege. Dordrecht / Boston / London, Kluwer Academic Publishers, (1994), pp. 163-184.

. Frege and Husserl: The ontology of Reference. Journal of the British Society for Phenomenology, vol. 9, n² 2, pp. 11-12, 1978.

- On the origins of Analytic Philosophy. Grazer Philosophische Studien, 34, pp. 153-173, 1989.

. Frege and Chomsky; Sense and Psychologism. In: BIRO, J. and KOTAKO, P. Frege: sense and reference one hundred years later. Dordrecht, Kluwer, 1995, pp. 25-46.

; WOODRUFF SMITH, D. The Cambridge Companion to Husserl. Cambridge, Cambridge University Press, 1995.

SOKOLOWSKY, R. Husserl and Frege. The Journal of Philosophy, LXXXIV, pp. 521-528, 1987.

STUART MILL, J. System of Logic (L). Raciocinative and inductive. New York. Harper and Brother Publishers, 1869.

Manuscrito - Rev. Int. Fil., Campinas, v. 37, n.2, pp. 357-413, jul.-dez. 2014. 
SKORUPSKI, J.: Mill on language and logic. In: SKORUPSKI, J. (ed.): The Cambridge Companion to Mill. Cambridge, Cambridge University Press, (1998).

SKORUPSKI, J. (ed.): The Cambridge Companion to Mill. Cambridge, Cambridge University Press, 1998. . John Stuart Mill. London, Routledge, 1989.

TIESZEN, R. The Philosophy of Arithmetic. Frege and Hussserl. In: HAAPARANTA, L. Mind, Meaning and Mathematics. Essays on the philosophical Views of Husserl and Frege. Dordrecht / Boston / London, Kluwer Academic Publishers, (1994), pp. 85-112.

TWARDOWSKY, K.: Zur Lehre vom Inhalt und Gegenstand der Vorstellung. Eine psychologische Untersuchung (IG). Wien, Hölder, 1894.

WEINER, J. Frege in Perspective. Ithaca, Cornell University Press, 1990.

WILLARD, D. The integrity of the mental Act: Husserlian Reflections of a Fregean Problem. In: HAAPARANTA, Leila: Mind, Meaning and Mathematics. Essays on the philosophical Views of Husserl and Frege. Dordrecht / Boston / London, Kluwer Academic Publishers, (1994), pp. 235-262.

. The paradox of logical Psychologism: Husserls way out. In: MOHANTY, J. N.: Readings on Edmund Husserl's Logical Investigation. The Hague, Martinus Nijhoff, (1977), pp. 43-54.

WINDELBAND, W. Präludien (P). Aufsätze und Rede zur Einleitung in die Philosophie. Tübingen, Mohr, 1884. 3a. ed. 1907.

WOODROF SMITH, D. Review of Mohanty's. Husserl and Frege. Journal of the history of the Behavioral Sciences, v. 20. Issue 3, pp. 248250, 1984. 
CRÍTICA AL PSICOLOGISMO Y CONCEPCIÓN DE SUBJETIVIDAD 413

WUNDT, W.: Logik(L). Eine Untersuchung der Prinzipien der Erkenntnis und der Methode wissenschaftlicher Forschung. 2 Bde. Tübingen, Verlag von Ferdinand Enke, 1893, 2. Aufl..

Manuscrito - Rev. Int. Fil., Campinas, v. 37, n.2, pp. 357-413, jul.-dez. 2014. 